\title{
Model of an integrated solar thermochemical reactor/reticulated ceramic foam heat exchanger for gas-phase heat recovery
}

\author{
Rohini Bala Chandran ${ }^{\mathrm{a}}$, Robert M. De Smith ${ }^{\mathrm{a}}$, and Jane H. Davidson ${ }^{\mathrm{a}, 1}$ \\ ${ }^{a}$ Department of Mechanical Engineering, University of Minnesota, Minneapolis, MN
}

${ }^{1}$ Corresponding author. Address: Department of Mechanical Engineering, University of Minnesota, Minneapolis, MN. Phone: 612-626-9850.

Email address: jhd@me.umn.edu 


\begin{abstract}
The efficiency of solar thermochemical cycles to split water and carbon dioxide depends in large part on highly effective gas phase heat recovery. To accomplish this goal, we present the design and analysis of the thermal and hydrodynamic performance of a counter-flow, tube-intube alumina heat exchanger operating at temperatures of $1500{ }^{\circ} \mathrm{C}$ and integrated with a solar thermochemical reactor for isothermal production of syngas via the ceria redox cycle. The heat exchanger tubes are filled with alumina reticulated ceramic to enhance heat transfer. The effects of foam morphology and heat exchanger size on heat transfer, pressure drop, and process solarto-fuel efficiency are explored by coupling a computational fluid dynamic model of the heat exchanger, including radiative transport, with the overall reactor energy balance. We examine foam pore densities of 10, 20 and 30 PPI, and porosities of $65-90 \%$. The 10 PPI foam yields the best heat transfer performance and lowest pressure drop, as the larger pores enhance radiative heat transfer and decrease fluid phase drag forces. Although lower porosity is preferred to improve solid phase conduction in the RPC, the tradeoff in heat transfer and pressure drop point to use of higher porosity foam. Optimization for solar-to-fuel reactor efficiency is achieved with 85-90\% porosity, 10 PPI RPC.
\end{abstract}

\title{
Keywords:
}

Reticulated porous ceramic, solar thermochemical, heat exchanger, cerium dioxide, CFD, radiation 


\section{Nomenclature}

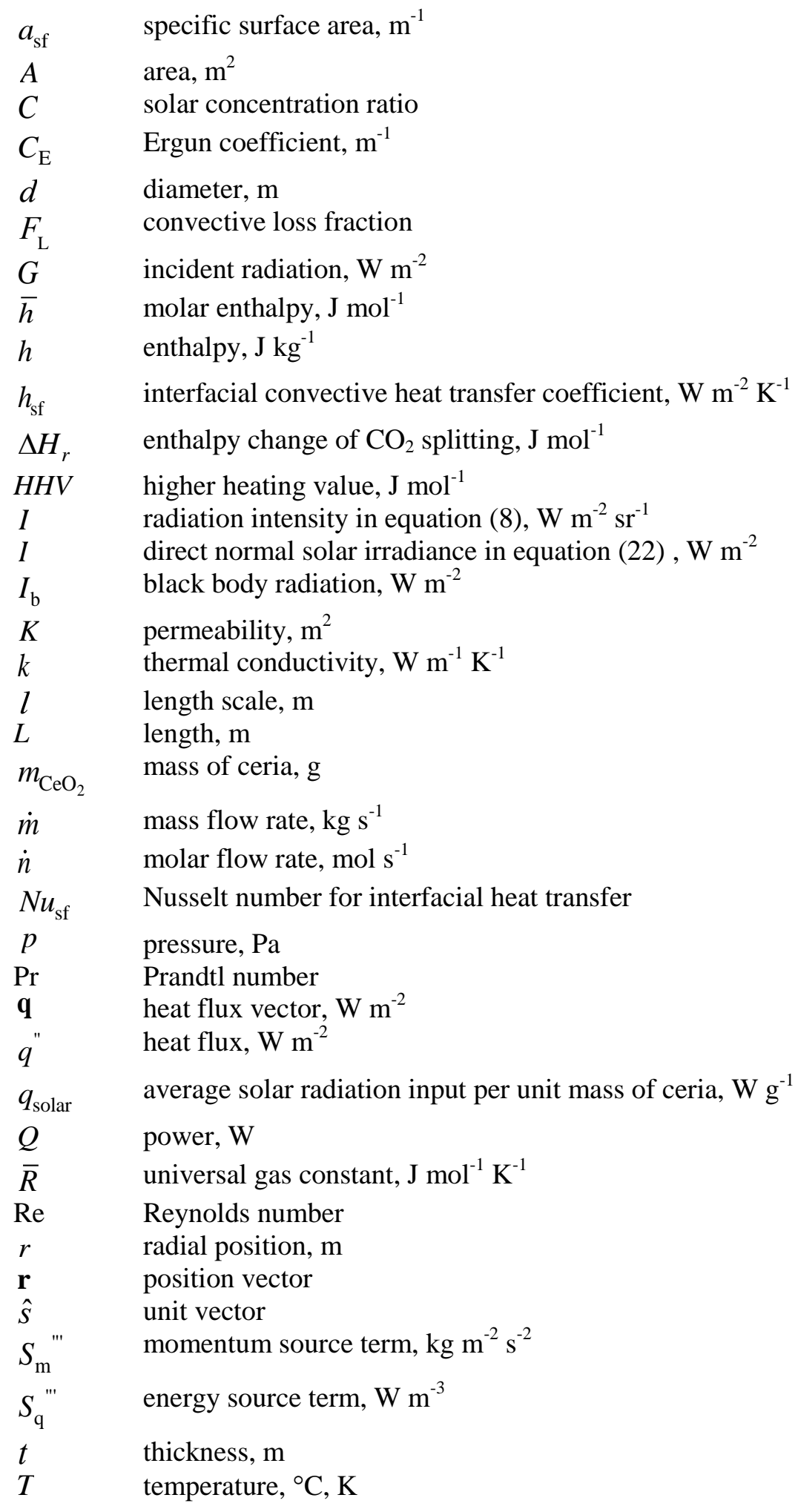



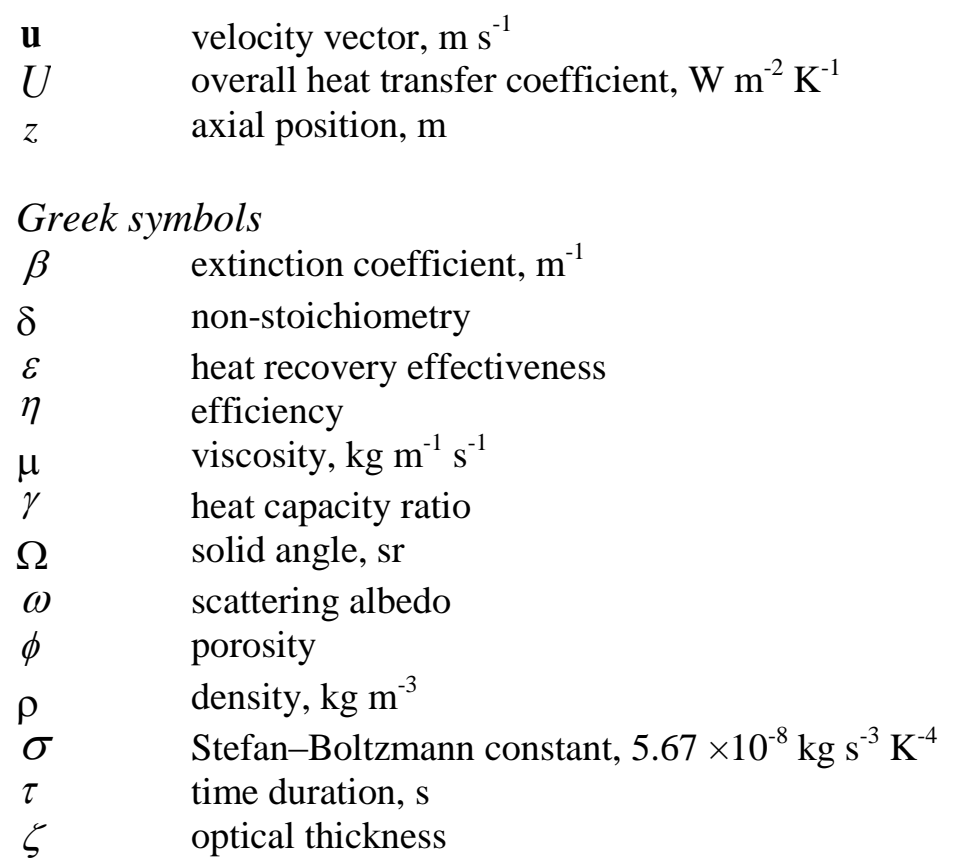

\section{Subscripts}

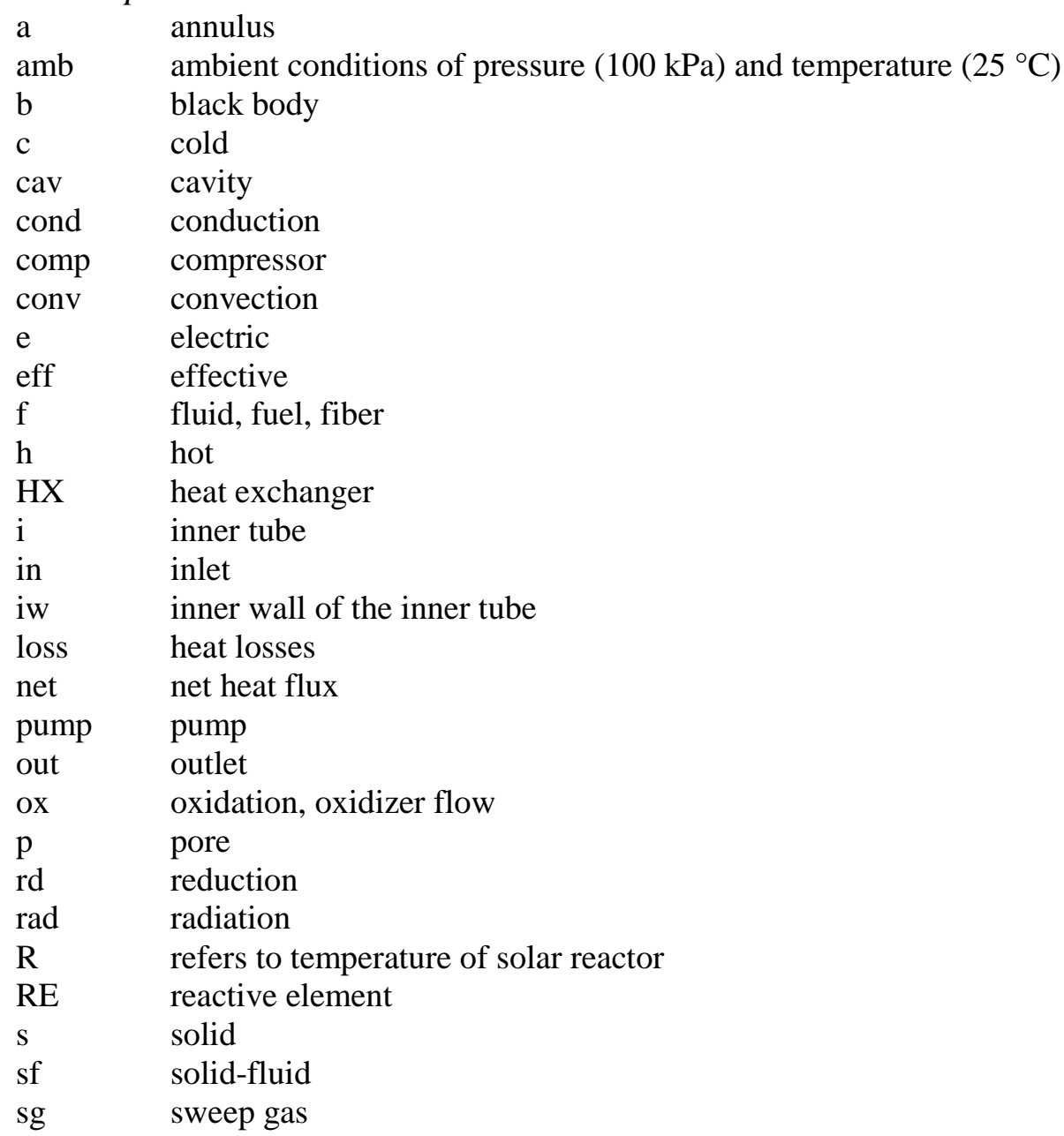




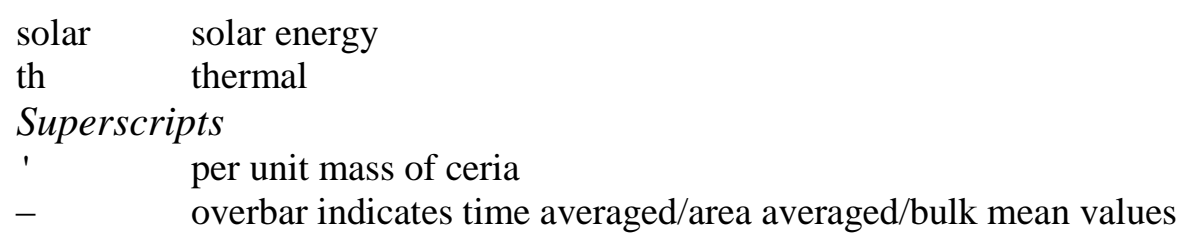

Abbreviations

CFD computational fluid dynamic

OD outer diameter

PPI pores per inch

RPC reticulate porous ceramic 


\section{Introduction}

Water and carbon dioxide splitting via thermochemical metal oxide reduction/oxidation cycles driven by concentrated solar energy is a promising means of storing solar energy in chemical bonds via the production of hydrogen or synthesis gas (a mixture of $\mathrm{H}_{2}$ and $\mathrm{CO}$ ). The products can be used directly in fuel cells or in the case of synthesis gas converted to liquid transportation fuels. In the present work we consider the non-stoichiometric cerium dioxide (ceria) cycle with a focus on the design of an integrated reactor/heat exchanger for gas-phase heat recovery. The ceria redox cycle consists of an endothermic reduction step (equation (1)) and an exothermic oxidation step with $\mathrm{CO}_{2}$ and/or $\mathrm{H}_{2} \mathrm{O}$ (equations (2a) and (2b)).

$$
\begin{gathered}
\mathrm{CeO}_{2-\delta_{\text {ox }}} \rightarrow \mathrm{CeO}_{2-\delta_{\mathrm{rd}}}+0.5\left(\delta_{\mathrm{rd}}-\delta_{\text {ox }}\right) \mathrm{O}_{2} \\
\mathrm{CeO}_{2-\delta_{\mathrm{rd}}}+\left(\delta_{\mathrm{rd}}-\delta_{\text {ox }}\right) \mathrm{CO}_{2} \rightarrow\left(\delta_{\mathrm{rd}}-\delta_{\text {ox }}\right) \mathrm{CO}+\mathrm{CeO}_{2-\delta_{\text {ox }}} \\
\mathrm{CeO}_{2-\delta_{\mathrm{rd}}}+\left(\delta_{\mathrm{rd}}-\delta_{\text {ox }}\right) \mathrm{H}_{2} \mathrm{O} \rightarrow\left(\delta_{\mathrm{rd}}-\delta_{\text {ox }}\right) \mathrm{H}_{2}+\mathrm{CeO}_{2-\delta_{\text {ox }}}
\end{gathered}
$$

Fuel production is related directly to the change in the number of oxygen vacancies, or equivalently non-stoichiometry of ceria, between reduction and oxidation $\left(\delta_{\mathrm{rd}}-\delta_{\mathrm{ox}}\right)$. Chemical thermodynamics favors reduction at high temperature $\left(1400-1600{ }^{\circ} \mathrm{C}\right)$ and low $\mathrm{O}_{2}$ partial pressure, and reoxidation at a lower temperature, typically $800-1100{ }^{\circ} \mathrm{C}[1,2]$. However, this approach creates the need for solid phase heat recovery to achieve high reactor efficiencies [3-5]. Another option is to carry out the process isothermally or with a much smaller swing in temperature between reduction and oxidation $\left(\sim 100-200{ }^{\circ} \mathrm{C}\right)$ [6-9]. Isothermal or "near isothermal" cycling eliminates or decreases the requirement for solid-phase heat recovery of the ceria and simplifies the design of reactor components due to reduced thermal stresses. However, in comparison with the larger temperature swing cycle, isothermal cycling requires a lower 
oxygen partial pressure during reduction to produce an equivalent amount of fuel. For both cycling options, the overall process solar-to-fuel efficiency is improved dramatically with effective gas phase heat recuperation of any inert sweep gas used to maintain a low $\mathrm{O}_{2}$ partial pressure during reduction and of the oxidizing gas $\left(\mathrm{H}_{2} \mathrm{O}\right.$ or $\left.\mathrm{CO}_{2}\right)$ [3-9]. To date, demonstrations of the ceria redox cycle in prototype reactors [10-13] have not included gas phase heat recovery.

The major challenges of designing a gas phase heat recovery system are operation at temperatures as high as $1500{ }^{\circ} \mathrm{C}$ in a highly oxidizing environment and close coupling of the heat exchanger with the solar reactor. The extreme operating temperature and the requirement for chemical compatibility with ceria and the oxidizing gases constrain the choice of materials for construction. While metals provide high thermal conductivity, the long-term service temperatures of even superalloys are no more than $950^{\circ} \mathrm{C}$ due to corrosion and the onset of creep $[14,15]$. Ceramic materials are an excellent alternative because they can withstand temperatures of 1500 $2500{ }^{\circ} \mathrm{C}$ [14-17]. Heat exchanger designs using ceramic materials have been developed for solar receivers [18], coal or oil fired steam turbines [16] and hydrogen production from sulfuric acid [15,19-21]. The prior work has focused on silicon carbide (SiC) due to its high mechanical strength (tensile strength of $250 \mathrm{MPa}$ at $1500^{\circ} \mathrm{C}$ ), low coefficient of thermal expansion $(5.5$ $\left.\times 10^{-6} \mathrm{~K}^{-1}\right)$, and high thermal conductivity $\left(\sim 25 \mathrm{~W} \mathrm{~m}^{-1} \mathrm{~K}^{-1}\right.$ at $\left.1500^{\circ} \mathrm{C}\right)$ as compared to other ceramics [16,22]. However, $\mathrm{SiC}$ oxidizes at the conditions anticipated in a reactor for reduction and oxidation of ceria [23-25] and has been observed to react vigorously with ceria at high temperatures [26]. In view of these factors, the present study considers the use of alumina tubes (tensile strength of $13 \mathrm{MPa}$, thermal expansion of $8.6 \times 10^{-6} \mathrm{~K}^{-1}$ and thermal conductivity of 6 $\mathrm{W} \mathrm{m}{ }^{-1} \mathrm{~K}^{-1}$ at $1500^{\circ} \mathrm{C}$ ) to contain the ceria in the reactor and as the material of construction of the heat exchanger. This approach mitigates the risk of mechanical failure due to differential thermal 
expansion. From the perspective of thermal design, the challenge is to provide high heat transfer surface area and effective radiative transport. Here we explore the use of open cell reticulated porous ceramic foam (RPC) as an effective solution.

We evaluate the impact of foam morphology (pore size and porosity) on heat transfer and pressure drop via a computational fluid dynamic (CFD) model of a counter flow tube-in-tube heat exchanger filled with RPC. Radiation has a strong impact on thermal transport, and the optical thickness of the RPC is low by design to reduce temperature gradients in the heat exchanger. Thus, the numerical model extends the scope of existing models of heat transfer for foam heat exchangers, which are largely restricted to metallic foams and either neglect radiative heat transfer [27-30] or model radiation with the diffusion approximation [31], thus restricting the results to large optical thicknesses $(>10)[32,33]$. Although radiative transport has been included in heat transfer models for ceramic foams used as volumetric solar receivers [34,35], the prior work is specific to $\mathrm{SiC}$ foams for operational temperatures less than $1200^{\circ} \mathrm{C}$.

The CFD model of the heat exchanger is coupled to an energy balance of a prototype solar reactor with the objective of sizing the heat exchanger in conjunction with selection of the mass of redox active material to achieve maximum solar-to-fuel efficiency.

\section{Integrated Reactor/Heat Exchanger Design}

Effective heat recovery for this application requires that the heat exchanger integrate directly with the solar reactor to eliminate thermal losses as gases flow to/from the reactor and the heat exchanger. Here we consider the integrated solar reactor/heat exchanger design illustrated in Figure 1(a). The cavity receiver is lined circumferentially with tubular reactive elements that contain the active redox material. In a $3 \mathrm{~kW}_{\text {th }}$ prototype under development, there are six reactive elements and the cavity has a diameter to length ratio of about 0.9 (length equals 
$0.347 \mathrm{~m}$ ) to maximize effective emissivity. The cavity is made of layers of ceramic insulation, which are chosen by considering the service temperature and thermal conductivity of commercially available materials. Concentrated sunlight enters the cavity through an aperture and is absorbed by the reactive elements. Each reactive element consists of concentric, high purity $(99.8 \%)$ alumina tubes. The outer tube has a closed spherical cap at the end located near the front of the reactor cavity. As shown in Figure 1(b), the annular gap is filled with $5 \mathrm{~mm}$ long and $5 \mathrm{~mm}$ diameter cylindrical porous ceria particles with micro-meter sized pores, and an internal porosity of $\sim 70 \%$. The overall bed void fraction is 0.4 . The porous particle bed provides high surface area for chemical reactions $\left(\sim 10^{5} \mathrm{~m}^{2} \mathrm{~m}^{-3}\right)$, facilitates rapid gas diffusion and yields acceptable pressure drop of less than 0.2 atm through each reactive element for the anticipated gas flow rates [8]. Each tube assembly extends through the rear of the cavity to form a tube-intube counter-flow heat exchanger (Fig. 1(b)). In the insulated heat exchanger, both the tube and annulus are filled with inert alumina RPC. Gases enter the inner tube of the heat exchanger at near ambient conditions (in the case of water splitting, the oxidizer enters as steam), flow through reactive element and then return to the heat exchanger through the annulus. During reduction, an inert sweep gas (such as $\mathrm{N}_{2}$ or Ar) is passed through the tubes (the sweep gas may be used in concert with a vacuum pump) to achieve low partial pressures of $\mathrm{O}_{2}$ over the ceria particles. During oxidation, the gas flow is switched to a flow of steam and/or $\mathrm{CO}_{2}$. In both steps of the cycle, heat is recovered from the gases leaving the reactor to preheat the gases entering the bed of ceria particles. The heat exchanger is well insulated to reduce thermal losses.

The reactor/heat exchanger design enables cyclic operation in either a continuous mode in which, for equal reduction and oxidation times, half of the reactive elements undergo 
reduction while the other half produce fuel, or a batch mode in which all reactive elements are simultaneously reduced and then reoxidized.

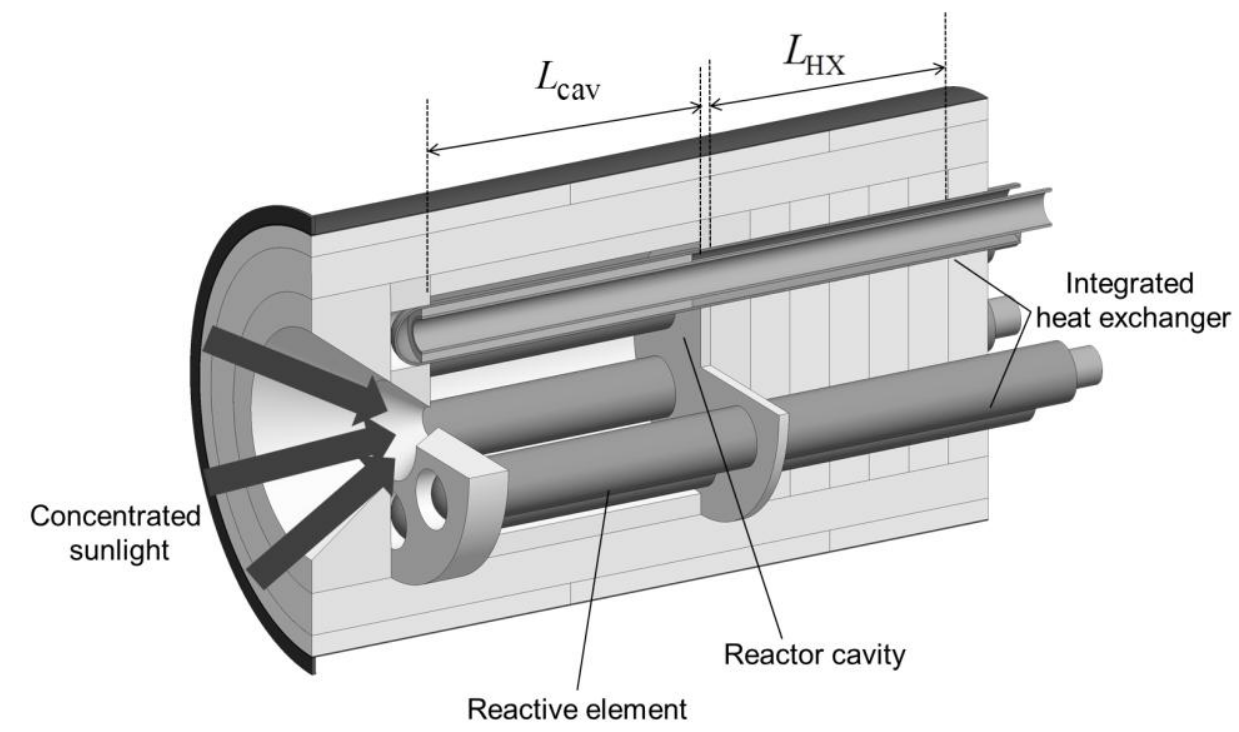

(a)

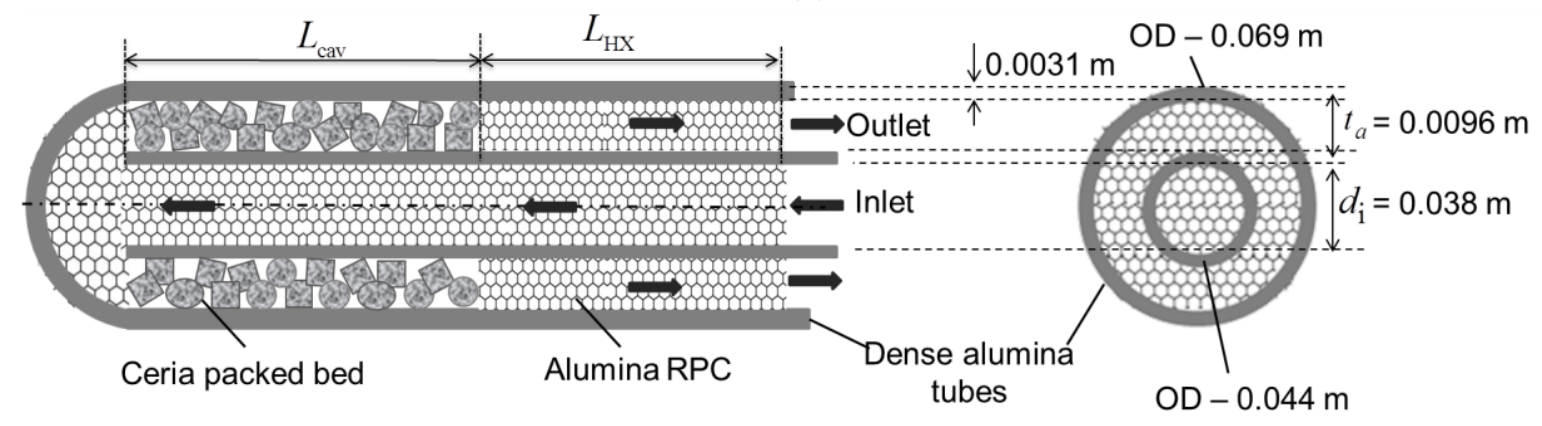

(b)

Figure 1. Schematic of (a) reactor prototype with reactive elements integrated with counter flow heat exchangers and (b) expanded cross-sectional views of the reactive element connected to the heat exchanger with specified geometric dimensions. Figures are not to scale.

\section{Analysis Approach}

\subsection{Heat Exchanger Model}

To characterize the effects of the porosity and pore size (quantified in terms of pores per inch, PPI) of the alumina RPC on heat transfer and pressure drop, we model the counterflow heat 
exchanger in Ansys Fluent (15.0). The two-dimensional, axisymmetric numerical domain with boundary conditions is shown in Figure 2. For both reduction and oxidation, gas is assumed to be ideal and compressible. Steady state continuum transport equations are applied for fluid flow and heat transfer. The RPC is considered homogenous and isotropic.

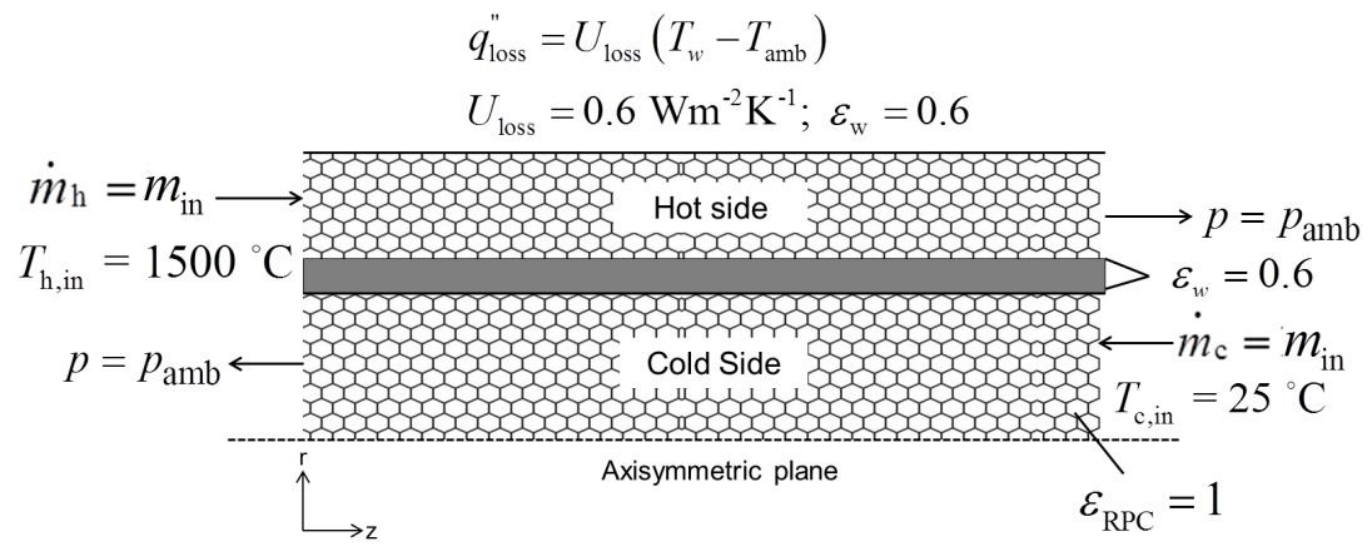

Figure 2. Numerical model domain of the heat exchanger with boundary conditions (figure is not to scale).

The mass and momentum conservation equations in the fluid phase are given by:

$$
\begin{gathered}
\nabla \cdot\left(\rho_{\mathrm{f}} \boldsymbol{u}\right)=0, \\
\nabla \cdot\left(\rho_{\mathrm{f}} \boldsymbol{u} \boldsymbol{u}\right)=-\nabla p+\nabla \cdot(\mu \nabla \boldsymbol{u}) \underbrace{-\frac{\mu}{K} \boldsymbol{u}-\rho_{\mathrm{f}} C_{E}|\boldsymbol{u}| \boldsymbol{u}}_{S_{\mathrm{m}}^{\prime \prime \prime}} .
\end{gathered}
$$

The source term in the momentum equation, $S_{m}^{\prime \prime}$, includes the pressure drop due to viscous forces from the pore walls and the inertial drag as given by the extended Darcy-BrinkmanForchheimer formulation [36].

A local thermal non-equilibrium formulation results in energy transport equations for the fluid and solid phases, given in equations (5) and (6).

$$
\nabla \cdot\left(\rho_{\mathrm{f}} \boldsymbol{u} h_{\mathrm{f}}\right)=\nabla \cdot\left(k_{\mathrm{f}, \mathrm{eff}} \nabla T_{\mathrm{f}}\right)+\underbrace{h_{\mathrm{sf}} a_{\mathrm{sf}}\left(T_{\mathrm{s}}-T_{\mathrm{f}}\right)}_{S_{\mathrm{q}}^{\prime \prime \prime}},
$$




$$
\nabla \cdot\left(k_{\mathrm{s}, \mathrm{eff}} \nabla T_{\mathrm{s}}\right)-\nabla \cdot \boldsymbol{q}_{\mathrm{rad}}-\underbrace{h_{\mathrm{sf}} a_{\mathrm{sf}}\left(T_{\mathrm{s}}-T_{\mathrm{f}}\right)}_{S_{\mathrm{q}}^{\prime \prime}}=0 .
$$

The rate of heat transfer between the solid and fluid phases, $S_{\mathrm{q}}^{\prime \prime}$, is expressed in terms of the specific surface area and the interfacial heat transfer coefficient. A user-defined scalar transport equation is modeled in Fluent to implement equation (6) on the same mesh generated for the fluid phase. The source terms, $S_{\mathrm{m}}^{\prime \prime \prime}$ and $S_{\mathrm{q}}^{\prime \prime \prime}$, are appropriately implemented by enforcing the positivity criterion $[37,38]$. Within the dense alumina inner tube, the steady-state conduction equation is solved and the wall surfaces of the tube are treated as opaque with a surface emissivity of 0.6 [39].

The alumina RPC is treated as an absorbing-scattering-emitting homogenous medium with isotropic, gray, diffuse radiative properties. The extinction coefficient is obtained using the geometric optics model proposed for RPC by Hsu and Howell [40,41]. The optical thickness, $\zeta=\beta l$, for the tube and annulus are defined using the foam extinction coefficient with the gap spacing, $t_{\mathrm{a}}$, and inner diameter, $d_{\mathrm{i}}$, as the respective length scales. Optical thickness is 1 to 8 for the annulus and 5 to 15 for the tube, depending on the PPI and porosity of the RPC. Within the annulus, $\zeta$ is not large enough to apply the Rosseland diffusion approximation [31]. Additionally, alumina RPCs are more scattering than absorbing based on prior measurements and an inverse radiation analysis [42]. Therefore, the $\mathrm{P}_{1}$ approximation of the radiative transport equation is well suited for this application as it allows for both scattering and absorption in the medium [43]. For an isotropically scattering medium, a Laplace equation of the form shown in equation (7) applies, where $G$ is the radiation incident on the representative elemental volume.

$$
\nabla \cdot\left(\frac{1}{\beta} \nabla G\right)-3 \beta(1-\omega)\left(G-4 \sigma T_{\mathrm{s}}^{4}\right)=0
$$




$$
G=\int_{0}^{4 \pi} I(\boldsymbol{r}, \hat{s}) d \Omega
$$

The radiative source term in equation (6) is then evaluated as

$$
\nabla \cdot \boldsymbol{q}_{\mathrm{rad}}=\beta(1-\omega)\left(4 \pi I_{b}-G\right) .
$$

The transport properties of the RPC $-K, C_{E}, k_{\mathrm{s}, \mathrm{eff}}, h_{\mathrm{sf}}, \beta$ and $\omega-$ depend on the three dimensional foam morphology, including the pore size distribution, strut diameter, connectivity of the solid struts, and cross-sectional area of nodes at the intersection of struts. The average diameter of the pores, $d_{\mathrm{p}}$, strut/fiber diameter, $d_{\mathrm{f}}$, and the specific surface area, $a_{\mathrm{sf}}$, are related to the PPI and porosity of the foam $[27,44,45]$ by

$$
\begin{gathered}
d_{\mathrm{p}}=\frac{0.0254}{\mathrm{PPI}} \\
d_{\mathrm{f}}=1.18 \sqrt{\frac{1-\phi}{3 \pi}} \frac{d_{\mathrm{p}}}{1-e^{-\left(\frac{1-\phi}{0.04}\right)}} \\
a_{\mathrm{sf}}=\frac{3 \pi d_{\mathrm{f}}\left(1-e^{-((1-\phi) / 0.04)}\right)}{\left(0.59 d_{p}\right)^{2}}
\end{gathered}
$$

The empirical correlation obtained by Bhattacharya et al. [44,45] for metallic foams is used to determine permeability. The inertial coefficient is calculated using the Ergun model [46].

$$
\begin{gathered}
\frac{K}{d_{p}^{2}}=0.00073(1-\phi)^{-0.224}\left(\frac{d_{f}}{d_{p}}\right)^{-1.11}, \\
C_{E}=\frac{0.3 a_{\mathrm{sf}}}{\phi^{3}} .
\end{gathered}
$$

The values of $K$ and $C_{\mathrm{E}}$ determined from equations (13) and (14) are within $15 \%$ of values predicted using the empirical correlations provided in [47-49].

The interfacial heat transfer coefficient is determined using the correlation developed by Zukauskas et al. [50] for an arrangement of staggered cylinders subjected to crossflow, 


$$
\begin{aligned}
& h_{\mathrm{sf}}=\frac{N u_{\mathrm{sf}} k_{\mathrm{f}}}{d}, \\
& N u_{s f}=0.76 \operatorname{Re}_{d}^{0.4} \operatorname{Pr}^{0.37}\left(1 \leq \operatorname{Re}_{d} \leq 40\right) .
\end{aligned}
$$

The local pore-scale Reynolds number, $\mathrm{Re}_{d}$, is defined using a length scale based on the fiber diameter [27],

$$
d=d_{\mathrm{f}}\left(1-e^{\frac{-(1-\phi)}{0.04}}\right) .
$$

The heat transfer coefficient obtained from equation (15) is within $10 \%$ of estimated values for $\mathrm{SiC}$ foams using tomographic images [49] and numerical simulations on ceramic foam structures [51].

The fluid phase effective thermal conductivity is given by $k_{\mathrm{f}, \text { eff }}=\phi k_{f}$. Of the various correlations that were considered for $k_{\mathrm{s}, \text { eff }}$ [44,52-54], Coquard et. al [55] and Kamuito [56] establish that the analytical expression obtained by Schuetz and Glicksman [54] for polyurethane foams is the most applicable, as it adequately (within $30 \%$ of experimental measurements) represents thermal conductivities of open cellular structures. The lower limit for $k_{\mathrm{s}, \text { fff }}$ in equation (17) is used in the model to obtain a conservative estimate of the heat transfer performance.

$$
0.8(1-\phi) \frac{k_{s}}{3}<k_{\mathrm{s}, \mathrm{fff}}<(1-\phi) \frac{k_{s}}{3} .
$$

The extinction coefficient and scattering albedo have been evaluated for 10, 20, 30 and 65 PPI alumina foams at only one porosity (70\%) in [42]. Spectral radiative properties of partially stabilized, reticulate zirconia and $\mathrm{SiC}$ foams have been obtained using a combination of experiments and inverse numerical techniques [41]. Thus, in the absence of available data to relate optical transport properties of alumina RPC as a function of foam PPI and porosity, we 
apply the correlations provided for zirconia foams [41]. The extinction coefficient, $\beta$, determined from [41] are within $25 \%$ of the predictions in [42]. A modified constant has been used in the geometric optics model to determine $\beta$ in [41], equation (18), and a range of 0.81-0.999 was obtained for the scattering albedo.

$$
\beta=\frac{4.4(1-\phi)}{d_{\mathrm{p}}} .
$$

The lower limit of $\omega=0.81$ is employed in the model and the sensitivity of heat transfer performance to $\omega$ was evaluated for $0.81 \leq \omega \leq 0.999$. The overall heat transfer coefficient changed less than $10 \%$ over this range.

The boundary conditions are shown in Figure 2. The mass flow rate and temperature of the gases are specified at the inlets of the hot (annulus) and cold (inner channel) sides of the heat exchanger. For the present simulations, the hot side inlet is fixed at $1500{ }^{\circ} \mathrm{C}$, which is the intended operating temperature of the reactor and the cold side inlet is fixed at $25^{\circ} \mathrm{C}$. The results are presented for $\mathrm{CO}_{2}$ splitting and $\mathrm{N}_{2}$ sweep gas. The gases are assumed to maintain a uniform composition in the heat exchanger $-\mathrm{N}_{2}$ with $10 \mathrm{ppm} \mathrm{O}_{2}$ during reduction and a mixture comprising $\mathrm{CO}_{2}$ and $\mathrm{CO}$ during oxidation. The inter-species transport is not modeled and the thermophysical properties (viscosity, thermal conductivity and specific heat) of the gas mixture are based on the local temperature [57,58], using a mixing rule with mole fraction as weighting function for the pure species. The surface emissivity of RPC alumina at the inlets and outlets is assumed to be $1-$ a reasonable selection considering the high temperatures near the reactor and roughness in the pore surfaces. The gases are stipulated to leave the domain at atmospheric pressure. A no-slip boundary condition is imposed on all solid walls. Temperature and heat flux continuity is imposed at the wall-fluid interfaces. In the prototype heat exchanger, the RPC is 
bonded to the alumina tubes but the model does not capture the effect of contact resistance. It is anticipated that in the presence of radiation, the effect of contact resistance between the tube wall and the RPC will be much less significant than it would be at lower temperature. The net heat flux on the tube wall surfaces (inner and outer) are evaluated as the sum of heat fluxes on the fluid and solid surfaces and by imposing thermal equilibrium at the boundary,

$$
\begin{gathered}
q_{w}^{\prime \prime}=\left.k_{\mathrm{s}, \mathrm{eff}} \frac{\partial T_{\mathrm{s}}}{\partial r}\right|_{r=r_{w}}+\left.k_{\mathrm{f}, \mathrm{eff}} \frac{\partial T_{\mathrm{f}}}{\partial r}\right|_{r=r_{\mathrm{w}}}, \\
\left.T_{\mathrm{s}}\right|_{r=r_{\mathrm{w}}}=\left.T_{\mathrm{f}}\right|_{r=r_{\mathrm{w}}}=\left.T_{\mathrm{w}}\right|_{r=r_{\mathrm{w}}} .
\end{gathered}
$$

These equations are implemented by using boundary profile user-defined functions in Fluent on the respective surfaces. For the outer tube surface, conduction losses through the insulation material surrounding the heat exchanger, $q_{\text {loss }}^{\prime \prime}$, are modeled as

$$
q_{\mathrm{loss}}^{\prime \prime}=U_{\mathrm{loss}}\left(T_{w}-T_{\mathrm{amb}}\right)
$$

where $U_{\text {loss }}$ is determined from 3-D simulations of steady-state conduction through the insulation surrounding the heat exchanger. For the incident radiation, Marshak's condition for direction integrated radiative heat flux is imposed at all wall boundaries [35,43].

The heat exchanger performance is quantified by the overall heat transfer coefficient, $U_{\mathrm{i}}$, and pressure drop, $\Delta p_{H X} . U_{\mathrm{i}}$ is evaluated based on the inner channel surface area $\left(A_{i}\right)$,

$$
U_{\mathrm{i}}=\frac{\dot{m}_{c}\left(h_{\mathrm{c}, \text { out }}-h_{\mathrm{c}, \text { in }}\right)}{A_{i}\left(\bar{T}_{\mathrm{c}}-\bar{T}_{\mathrm{h}}\right)},
$$

where $\bar{T}_{\mathrm{c}}$ and $\bar{T}_{\mathrm{h}}$ are the bulk mean temperatures of the cold and hot side streams, respectively, and the numerator is the rate of energy transferred to the cold stream or the heat duty of the heat exchanger. The impact of foam morphology on $U_{\mathrm{i}}$ and $\Delta p_{H X}$ is examined for 10, 20 and 30 PPI and porosities varying from 65 to $90 \%$. 
The conjugate heat transfer model was solved in Fluent with a mapped mesh of quadrilateral elements. A maximum of 12000 (60 radial $\times 200$ axial) elements were created, with finer elements close to the solid walls. Grid independence in the axial and radial directions was established by independently varying the grid size in each direction. The PISO algorithm was used to couple the pressure and velocity fields [59]. A second order upwind method was applied for the advection terms in the momentum, energy (fluid and solid phase), and incident radiation equations. Large magnitudes of source terms in the energy transport equations, due to the interfacial heat transfer between the solid and fluid phases and radiation, were resolved by using an under-relaxation factor of 0.985 for the energy equations. The under-relaxation factor was selected by progressive reduction of values from 1 until smooth convergence of the residuals was obtained. The local thermal non-equilibrium formulation for energy transport and the nature of heat flux boundary conditions necessitate numerous iterations (up to 20000) to achieve a steadystate solution. To speed the solution, the mesh was partitioned using the Metis method and verified to ensure load balancing on eight nodes on an Intel Xeon X5690 (4.1 GHz, 12 GB) core $[38,59]$. The governing equations were solved in a sequential manner with the globally scaled residual values for convergence set to $10^{-10}$ for all transport equations, including radiative transfer. Additionally, the gas bulk mean temperatures at the cold side and hot side exits were monitored to be constant for 100 iterations after the solution converged.

\subsection{Integrated Reactor/Heat Exchanger}

The design of the reactor and heat exchanger is specified by determining the mass of ceria, the RPC morphology and the length of the heat exchanger that provide the best efficiency. The mass of ceria contained within the reactive elements and the effectiveness of gas phase heat 
recuperation (and thus heat exchanger design) are linked through an overall energy balance on the system:

$$
\begin{aligned}
q_{\mathrm{solar}}= & \frac{\sigma T_{R}^{4}}{C I} q_{\mathrm{solar}}+F_{L} q_{\mathrm{solar}}\left(1-\frac{\sigma T_{R}^{4}}{C I}\right)+\left.\overline{\dot{n}}_{f}{ }^{\prime} \Delta H_{r}\right|_{T_{R}}+ \\
& \dot{n}_{\mathrm{sg}}{ }^{\prime}\left(\frac{\tau_{\mathrm{rd}}}{\tau_{\mathrm{rd}}+\tau_{\mathrm{ox}}}\right)\left[\bar{h}_{\mathrm{sg}}\left(T_{R}\right)-\bar{h}_{\mathrm{sg}}\left(T_{\mathrm{sg}, \text { out }}\right)\right]+\dot{n}_{\mathrm{ox}}{ }^{\prime}\left(\frac{\tau_{\mathrm{ox}}}{\tau_{\mathrm{rd}}+\tau_{\mathrm{ox}}}\right)\left[\bar{h}_{\mathrm{ox}}\left(T_{R}\right)-\bar{h}_{\mathrm{ox}}\left(T_{\mathrm{ox}, \text { out }}\right)\right] .
\end{aligned}
$$

Each term in the energy balance is evaluated per unit mass of ceria and is averaged over a cycle. The total solar energy input to the reactor, $Q_{\text {solar }}$, is held fixed at $3 \mathrm{~kW}_{\text {th }}$ to model the prototype reactor under development and thus the total mass of ceria that can be utilized in the prototype (split between the six reactive elements) is given by

$$
m_{\mathrm{CeO}_{2}}=\frac{3000 \mathrm{~W}}{q_{\mathrm{solar}}}
$$

The first term on the right hand side of equation (22) represents reradiation losses from the cavity, assuming a black cavity receiver and a concentration ratio $(C)$ of $3000\left(3 \mathrm{MW} \mathrm{m}^{-2}\right)$, a good choice for operation at $1500{ }^{\circ} \mathrm{C}[6]$. The second term represents convective losses from the reactor as a fraction $\left(F_{L}\right)$ of the absorbed solar input. Here, $F_{L}$ is assumed to be 0.2 , consistent with losses reported in [60].

The third term represents the power requirement of producing the fuel, where $\left.\Delta H_{r}\right|_{T_{R}}$ is the enthalpy change of the $\mathrm{CO}_{2}$ splitting reaction, evaluated at the isothermal reactor temperature of $1500{ }^{\circ} \mathrm{C}$. The mass-specific fuel production rate averaged over one cycle, $\overline{\dot{n}}_{f}{ }^{\prime}$, is $0.078 \mu \mathrm{mol}$ $\mathrm{s}^{-1} \mathrm{~g}^{-1}$ based on measured data obtained in a small scale reactive element at $1500^{\circ} \mathrm{C}$, and 1 bar for reduction and oxidation periods ( $\tau_{\mathrm{rd}}$ and $\tau_{\mathrm{ox}}$ ) of $100 \mathrm{~s}$ each [8]. The key to applying this mass specific rate to the larger reactive element is the application of chemical similitude, as detailed by Venstrom et al. [8]. The three relevant dimensionless parameters for similitude are 
the aspect ratio (the ratio of the ceria particle bed length to its radius), the Peclet number (the ratio of the characteristic gas diffusion time to the gas residence time), and the Damköhler number (the ratio of the gas residence time to the characteristic reaction time). Matching the Damköhler number is most important for similitude in this problem; for data reported in [8], with similar Damköhler the average fuel production rate was constant even with a three-fold difference in aspect ratio and a factor of 20 difference in Peclet numbers. In the present analysis, we match the Damköhler number by matching the ceria-mass-specific sweep gas and $\mathrm{CO}_{2}$ flow rates used in the prior experiments. The mass-specific flow rates of sweep gas and oxidizer are fixed at $\dot{n}_{\mathrm{sg}}{ }^{\prime}=1 \times 10^{-4} \mathrm{~mol} \mathrm{~s}^{-1} \mathrm{~g}^{-1}$ and $\dot{n}_{\mathrm{ox}}{ }^{\prime}=3.3 \times 10^{-5} \mathrm{~mol} \mathrm{~s}^{-1} \mathrm{~g}^{-1}$ based on the data and optimization procedure presented in [8].

The fourth and fifth terms in equation (22) represent the sensible heating requirements of the sweep gas (during reduction) and oxidizer (during oxidation), which depend on the heat exchanger effectiveness during reduction and oxidation respectively.

$$
\begin{gathered}
\varepsilon_{\mathrm{rd}}=\frac{\left(\bar{h}_{\mathrm{sg}}\left(T_{\mathrm{sg}, \mathrm{out}}\right)-\bar{h}_{\mathrm{sg}}\left(T_{\mathrm{amb}}\right)\right)}{\left(\bar{h}_{\mathrm{sg}}\left(T_{R}\right)-\bar{h}_{\mathrm{sg}}\left(T_{\mathrm{amb}}\right)\right)} \\
\varepsilon_{\mathrm{ox}}=\frac{\dot{n}_{\mathrm{ox}, \text { in }}\left(\bar{h}_{\mathrm{ox}, \text { in }}\left(T_{\mathrm{ox}, \mathrm{out}}\right)-\bar{h}_{\mathrm{ox}, \text { in }}\left(T_{\mathrm{amb}}\right)\right)}{\dot{n}_{\mathrm{ox}, \text { out }}\left(\bar{h}_{\mathrm{ox}, \text { out }}\left(T_{R}\right)-\bar{h}_{\mathrm{ox}, \text { out }}\left(T_{\mathrm{amb}}\right)\right)}
\end{gathered}
$$

The CFD model of the heat exchanger is implemented to solve for the temperatures of the sweep gas and oxidizer after they are preheated in the heat exchanger, $T_{\mathrm{sg}, \text { out }}$ and $T_{\mathrm{ox}, \mathrm{out}}$. The values of the total flow rates of sweep gas and oxidant and the corresponding effectivenesses of the heat exchanger are determined by iteration between the heat exchanger model and the reactor energy balance. The convergence criterion is that the heat recovery effectiveness changes by less than $0.1 \%$ between iterations, corresponding to a change in ceria mass of less than $100 \mathrm{~g}$. 
This iterative procedure is carried out for a range of RPC morphologies and heat exchanger lengths to identify the ceria mass and heat exchanger geometry that maximizes solarto-fuel efficiency for the assumed values of mass-specific fuel production, flow rates, and cycle duration. The time-averaged solar-to-fuel efficiency is defined as:

$$
\eta=\frac{\overline{\dot{n}}_{f} \times H H V_{f}}{Q_{\text {solar }}+Q_{\text {pump }}}=\frac{\left(\overline{\dot{n}}_{f}^{\prime} \times m_{\mathrm{CeO}_{2}}\right) \times H H V_{f}}{q_{\text {solar }} \times m_{\mathrm{CeO}_{2}}+Q_{\text {pump,rd }}+Q_{\text {pump,ox }}} .
$$

The numerator is the product of the average $\mathrm{CO}$ production rate over a cycle and the higher heating value of the fuel. The denominator includes the fixed solar input of $3 \mathrm{~kW}_{\text {th }}$ plus the pumping power requirement, $Q_{\text {pump }}$, which is the sum of pumping power for reduction $Q_{\text {pump,rd }}$ and oxidation $Q_{\text {pump,ox }}$. Prior reports of experimentally determined solar-to-fuel efficiency have not included pumping power explicitly but rather lump pumping power with the parasitic power required for inert gas separation via cryogenic air separation [11-13], which delivers the sweep gas at a fixed pressure [61]. This approach does not capture the tradeoff in heat transfer and pumping power of the heat exchanger in overall process efficiency. The theoretical minimum energy requirements for producing sweep and oxidizer gases, assuming that the outlet streams are recycled [6], are small $(<45 \mathrm{~W})$ compared to the other terms in the denominator and therefore neglected in the present analysis. The authors acknowledge that the theoretical minimum work needed to produce the inert gas is less than the current industrial standard for air separation and thus efforts to reduce the amount of sweep gas required for the redox cycle are warranted.

The thermal equivalent of pumping power is 


$$
Q_{\text {pump }, j}=\frac{\overline{\dot{n}}_{j}\left(\frac{\gamma_{j}}{\gamma_{j}-1}\right) \bar{R} T_{0}\left\lfloor\left(\frac{p_{\mathrm{atm}}+\Delta p_{j}}{p_{\mathrm{atm}}}\right)^{\frac{\gamma_{j}-1}{\gamma_{j}}}-1\right\rfloor}{\eta_{\text {th-e }} \eta_{\text {comp }}} .
$$

The numerator is the average isentropic pumping power required to overcome the pressure drop $\Delta p_{j}$ across both the heat exchanger (determined by the heat exchanger model) and the reactive element. The pressure drop across the reactive element is determined by applying the DarcyForchheimer formulation [36], assuming negligible flow through the micrometer sized internal pores of ceria particles, with the packed bed permeability $\left(K_{\mathrm{RE}}=2.5 \times 10^{-8} \mathrm{~m}^{2}\right)$ and inertial coefficient $\left(C_{\mathrm{E}, \mathrm{RE}}=3281 \mathrm{~m}^{-1}\right)$ estimated from the Carmen-Kozeny [36] and Ergun [46] models respectively. The reactive element length is varied to accommodate the required mass of ceria. The denominator accounts for the isentropic efficiency of the compressor, $\eta_{\text {comp }}=0.8$ [62], and converts the pumping power to a solar thermal equivalent with a thermal-to-electric efficiency of $\eta_{\text {th-e }}=0.2[63]$. As will be shown by the results, pumping power is an important consideration for both inert and oxidizing gases. This statement is particularly true when using gas flow rates commensurate with measured rates of reaction rather than assumed idealistic models for flow, such as the counterflow model used in several thermodynamic analyses [6,9].

Table 1 lists the fixed parameters used in the reactor efficiency calculation.

Table 1. Parameters fixed in the reactor energy balance and efficiency calculation

\begin{tabular}{cc}
\hline Parameter & Value \\
\hline$T_{R}$ & $1773 \mathrm{~K}$ \\
$T_{\mathrm{amb}}$ & $298 \mathrm{~K}$ \\
$C$ & 3000 \\
$I$ & $1000 \mathrm{~W} \mathrm{~m}^{-2}$ \\
$F_{L}$ & 0.2 \\
$\overline{\dot{n}}_{f}{ }^{\prime}$ & $0.078 \mu \mathrm{mol} \mathrm{s}^{-1} \mathrm{~g}^{-1}$
\end{tabular}




\begin{tabular}{cc}
$\overline{\dot{n}}_{s g}{ }^{\prime}$ & $50 \mu \mathrm{mol} \mathrm{s}^{-1} \mathrm{~g}^{-1}$ \\
$\overline{\dot{n}}_{o x}{ }^{\prime}$ & $16 \mu \mathrm{mol} \mathrm{s}^{-1} \mathrm{~g}^{-1}$ \\
$Q_{\text {input }}$ & $3000 \mathrm{~W}$ \\
$\eta_{\text {th-e }}$ & 0.2 \\
$\eta_{\text {comp }}$ & 0.8 \\
$\tau_{\text {rd }}$ & $100 \mathrm{~s}$ \\
$\tau_{\text {ox }}$ & $100 \mathrm{~s}$ \\
$p_{\text {amb }}$ & $100 \mathrm{kPa}$ \\
\hline
\end{tabular}

\section{Results}

\subsection{Effect of Foam Morphology}

As a first step in the specification of foam morphology, the influence of porosity and PPI on the overall heat transfer coefficient and pressure drop was explored for a fixed mass flow rate of sweep gas $\left(1.8 \times 10^{-3} \mathrm{~kg} \mathrm{~s}^{-1}\right)$, corresponding to a mass of $\sim 3800 \mathrm{~g}$ of ceria, and $1.4 \mathrm{~m}$ long heat exchanger. The overall heat transfer coefficient is insensitive to flow rate over the range relevant to this study $\left(3 \times 10^{-3} \mathrm{~kg} \mathrm{~s}^{-1}\right.$ to $\left.5 \times 10^{-3} \mathrm{~kg} \mathrm{~s}^{-1}\right)$ as the flow is laminar $\left(80<\mathrm{Re}_{d_{i}}<500\right)$. The inlet temperature on the hot side of the heat exchanger is $1500^{\circ} \mathrm{C}$ in accordance with the high temperature required for reduction of ceria. The inlet gas temperature is anticipated to influence the heat recovery effectiveness, due to the significance of radiation.

The results shown in Figure 3 for 10, 20 and 30 PPI for $65 \% \leq \phi \leq 90 \%$ suggest that the 10 PPI foam provides the best performance for all porosities considered. For reference, results are also provided for a heat exchanger without foam, indicated by dashed lines in the plots. First, consider the heat transfer performance (Figure 3(a)). The overall heat transfer coefficients for foam filled heat exchangers are at least twenty times greater than the tubular heat exchanger without RPC, and increase as porosity and PPI are decreased. The 10 PPI foam delivers higher overall heat transfer than the 20 and 30 PPI foam due to enhanced radiative transport in the 
larger pores. This enhancement in heat transfer with lower PPI is achieved even with a reduction in specific surface area for heat exchange between the solid and the fluid phases (e.g., $a_{\mathrm{sf}}=1587$ $\mathrm{m}^{-1}$ and $3174 \mathrm{~m}^{-1}$ for 10 and 20 PPI foams at $85 \%$ porosity). From this result we infer that even for the 10 PPI foam, the thermal resistance to interfacial heat transfer is low compared to the conductive and radiative resistances (pore-scale $\mathrm{Re}_{d}<25$ and $k_{\mathrm{f}} / k_{\mathrm{s}}>0.01$ for all cases considered). Even though the penetration of radiation improves for higher porosities, the lowest porosity of $65 \%$ yields the greatest heat transfer for all PPI due to improved conduction of the RPC solid phase. For the flow rates considered here, conduction and radiation are more significant than convective heat transfer.

As shown in Figure 3(b), the 10 PPI foam also provides the lowest pressure drop due to the reduction in viscous and inertial drag forces in the larger pores. Increasing porosity also reduces pressure drop due to higher foam permeability and reduced inertial losses. Although Figure 3(a) supports the choice of low porosities to augment thermal performance, Figure 3(b) makes evident the corresponding penalty due to higher pressure drop.

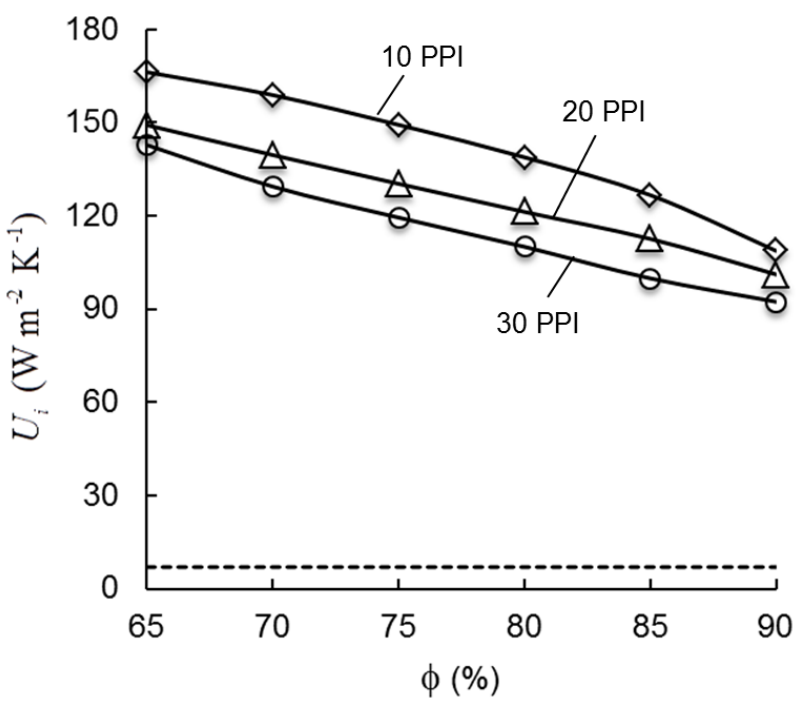

(a)

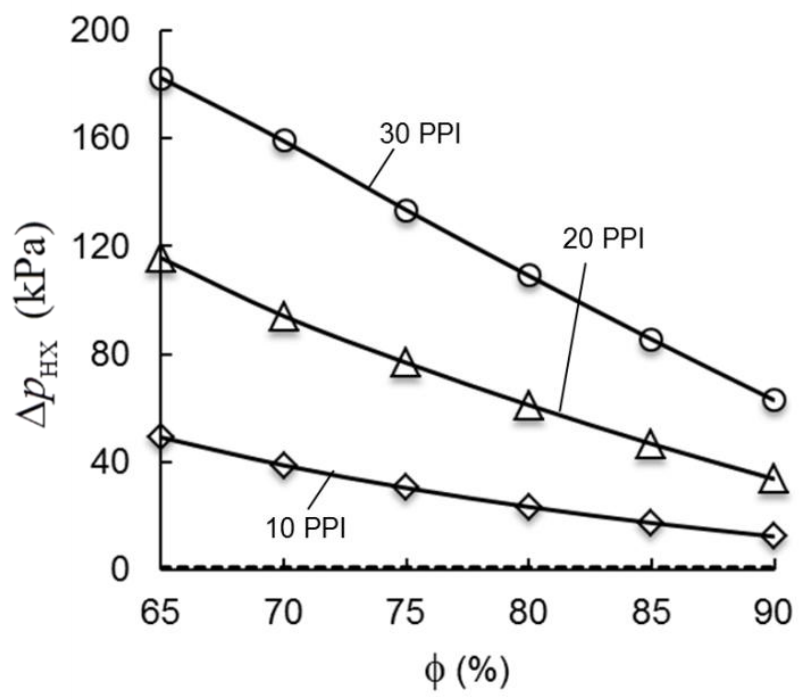

(b) 
Figure 3. Effect of foam PPI and $\phi(\%)$ on (a) $U_{i}$ and (b) $\Delta p_{\mathrm{HX}}$ for fixed sweep gas flow rate of $1.8 \times 10^{-3} \mathrm{~kg} \mathrm{~s}^{-1}$ and a $1.4 \mathrm{~m}$ long heat exchanger. Simulations are performed at selected porosities shown by the markers (lines are drawn as a visual aid).

To illustrate the relative contributions of radiative transport, conduction in the solid phase and fluid phase convection, the axial variation of heat fluxes at the inner tube inner wall is depicted in Figure 4 for 10 and 20 PPI RPC with $65 \%$ and 90\% porosities. Radiative transport is most significant near the hot side inlet $(\mathrm{z}=0)$ and decreases with decreasing temperature as heat is transferred from the hot gas exiting the reactor to the cold side gas flowing into the reactor. For both 65 and 90\% porosity, radiative heat transfer is enhanced in the larger pores of the 10 PPI foam because $\beta$ decreases (equation (18)), which in turn augments the rate of diffusion of thermal radiation in the medium (equation (7)). Because $\beta$ also decreases with increasing porosity (equation (18)), the radiative heat flux is highest for $\phi=90 \%$. The conductive flux is similar in magnitude for the 10 and 20 PPI foams, but is improved with decreased porosity because of the increase in average effective thermal conductivity, $\bar{k}_{\mathrm{s}, \text { eff }}$. For example, the average effective thermal conductivity increases from $0.3 \mathrm{~W} \mathrm{~m}^{-1} \mathrm{~K}^{-1}$ for $90 \%, 10$ PPI to $1 \mathrm{~W} \mathrm{~m}^{-1}$ $\mathrm{K}^{-1}$ for $65 \%, 10$ PPI. The conductive fluxes increase slightly near the cold side inlet $(\mathrm{z}=1.4 \mathrm{~m})$ due to increase in $k_{\mathrm{s}, \text { eff }}$ as the gases cool down. The reduction in viscous and inertial drag associated with the higher porosity results in a near doubling of convective fluxes at $\phi=90 \%$ as compared to $65 \%$ porosity, but even in this case heat transfer is predominately driven by conduction and radiation. As conductive heat transfer overshadows radiation and convection over a majority of the heat exchanger length for all PPI, the effect of weakened solid phase conduction at high porosities is to decrease the overall heat transfer coefficient despite better radiation and convection. 


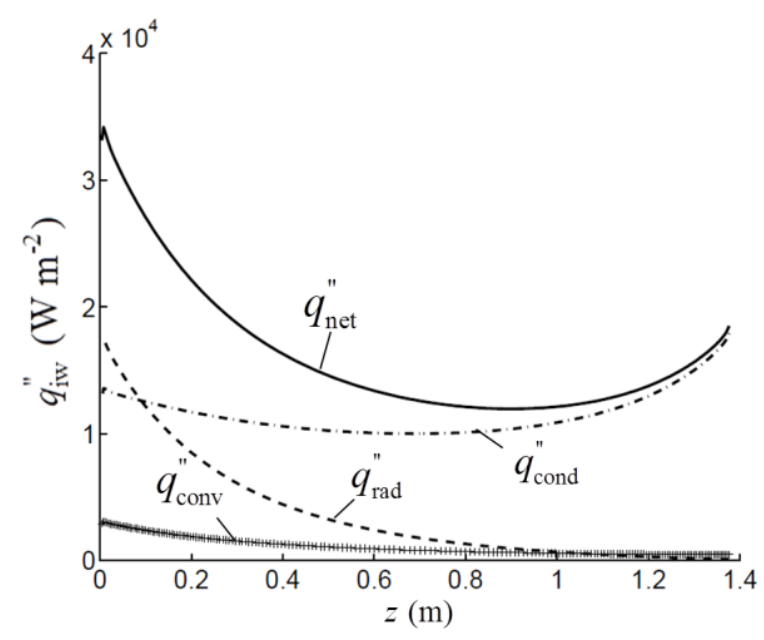

(a)

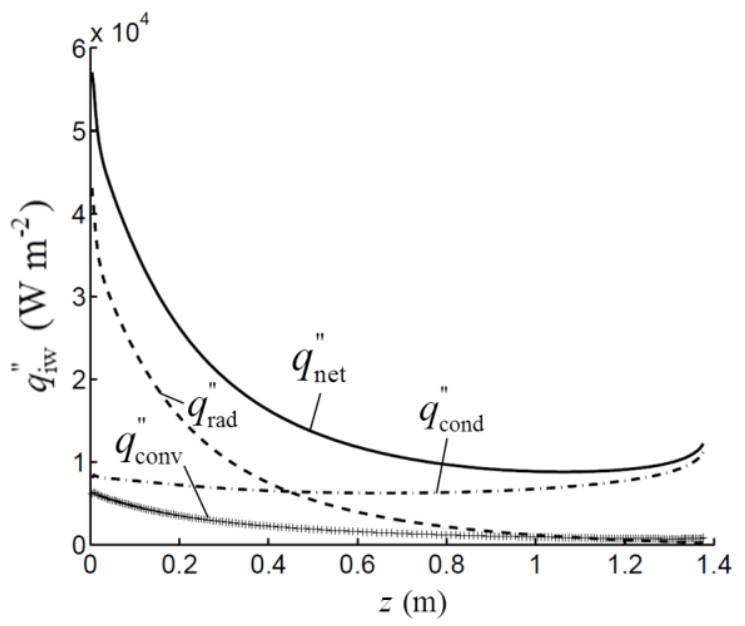

(c)

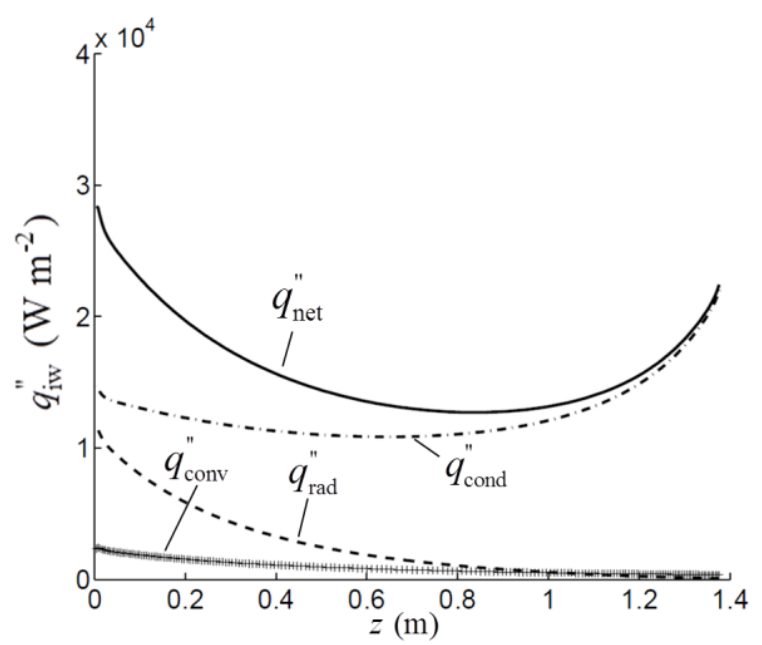

(b)

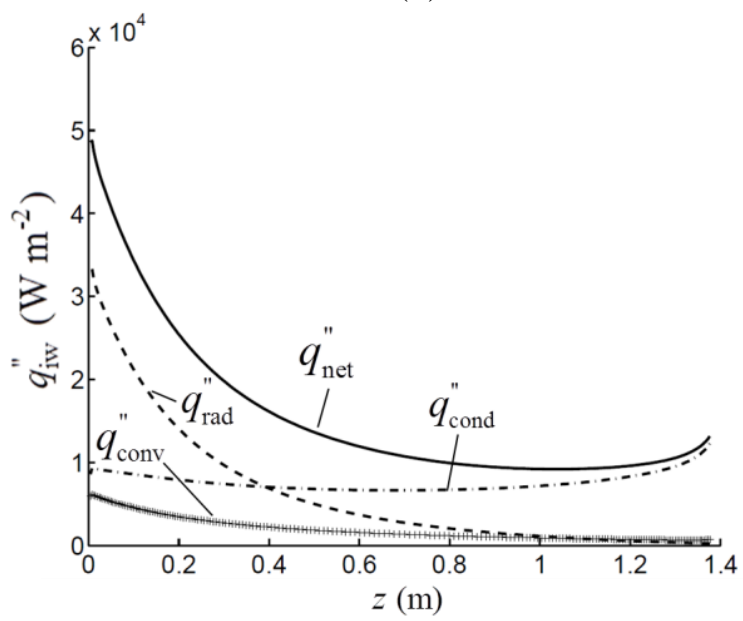

(d)

Figure 4. Axial variation of heat fluxes at the inner tube inner wall, during reduction with gas flow rate of $1.8 \times 10^{-3} \mathrm{~kg} \mathrm{~s}^{-1}$, in a $1.4 \mathrm{~m}$ long heat exchanger filled with RPC morphologies of $65 \%$ porosity, (a) 10 PPI and (b) 20 PPI ; 90\% porosity, (c) 10 PPI and (d) 20 PPI.

Figures 5(a) and 5(b) show the cold side gas phase radial temperature distributions normalized by the inner tube inner wall temperature, $T_{\mathrm{iw}}$, at $\mathrm{z}=0.1$ and $\mathrm{z}=0.7$ respectively, for 10 and 20 PPI foams with $\phi=65 \%$ and $\phi=90 \%$. The solid and gas phase temperatures are within $3^{\circ} \mathrm{C}$ for the $10 \mathrm{PPI}$ foam and even closer for larger PPI. Therefore, only the gas phase temperatures are shown in the plots. The radial temperature distributions are relatively uniform at $\mathrm{z}=0.1$ (Figure 5(a)) due to enhanced radiative transport in the hotter section of the heat exchanger. At both axial locations, the 10 PPI foam with $65 \%$ porosity exhibits the most uniform 
temperature distribution due to better solid phase conduction. At $\mathrm{z}=0.7 \mathrm{~m}$, the shape of the temperature profiles (Figure 5(b)) is influenced more by solid phase conduction as illustrated in Figure 4 and hence the profiles are steeper for $\phi=90 \%$ due to the diminished thermal conductivity, $k_{\mathrm{s}, \text { eff }}$, for both pore sizes. The radial temperature profiles are largely unaltered with changes in pore size as $k_{\mathrm{s}, \mathrm{eff}}$ remains constant.

The axial bulk-mean gas temperatures are shown in Figure 6 for 10 PPI, 90\% porous foam. For the assumed sweep gas flow rate of $1.8 \times 10^{-3} \mathrm{~kg} \mathrm{~s}^{-1}$ and $L_{\mathrm{HX}}=1.4 \mathrm{~m}$, the cold-side gas leaves the heat exchanger and enters the reactor at $1320^{\circ} \mathrm{C}$, resulting in heat recovery effectiveness of $87 \%$. For the same operating conditions, the predicted heat exchanger effectiveness is $90 \%$ for the $10 \mathrm{PPI}, 65 \%$ porous foam. With only a modest increase in heat recuperation in the low porosity foam, there is a heavy penalty in the pressure drop (49 $\mathrm{kPa}$ versus $13 \mathrm{kPa}$ for $\phi=90 \%$ ).

In summary, we down selected 10 PPI foam for further evaluation as it provides the best balance of heat transfer and pressure drop. Larger pore sizes, for example a 5 PPI foam (nominal pore diameter of $5.1 \mathrm{~mm}$ ) may provide an additional benefit in the inner tube but are likely unsuitable for the narrow annular gap $(9.6 \mathrm{~mm})$. The selection of porosity and overall heat exchanger length require consideration of reactor efficiency. 


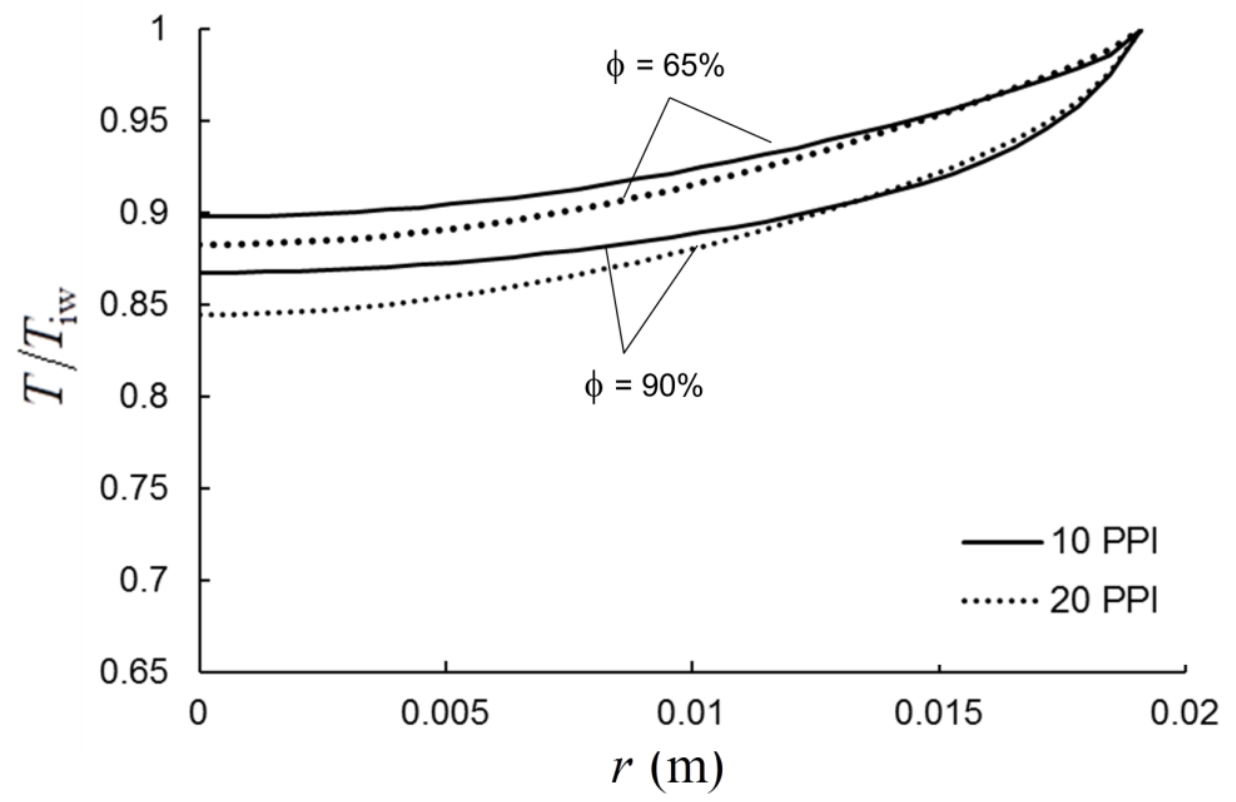

(a)

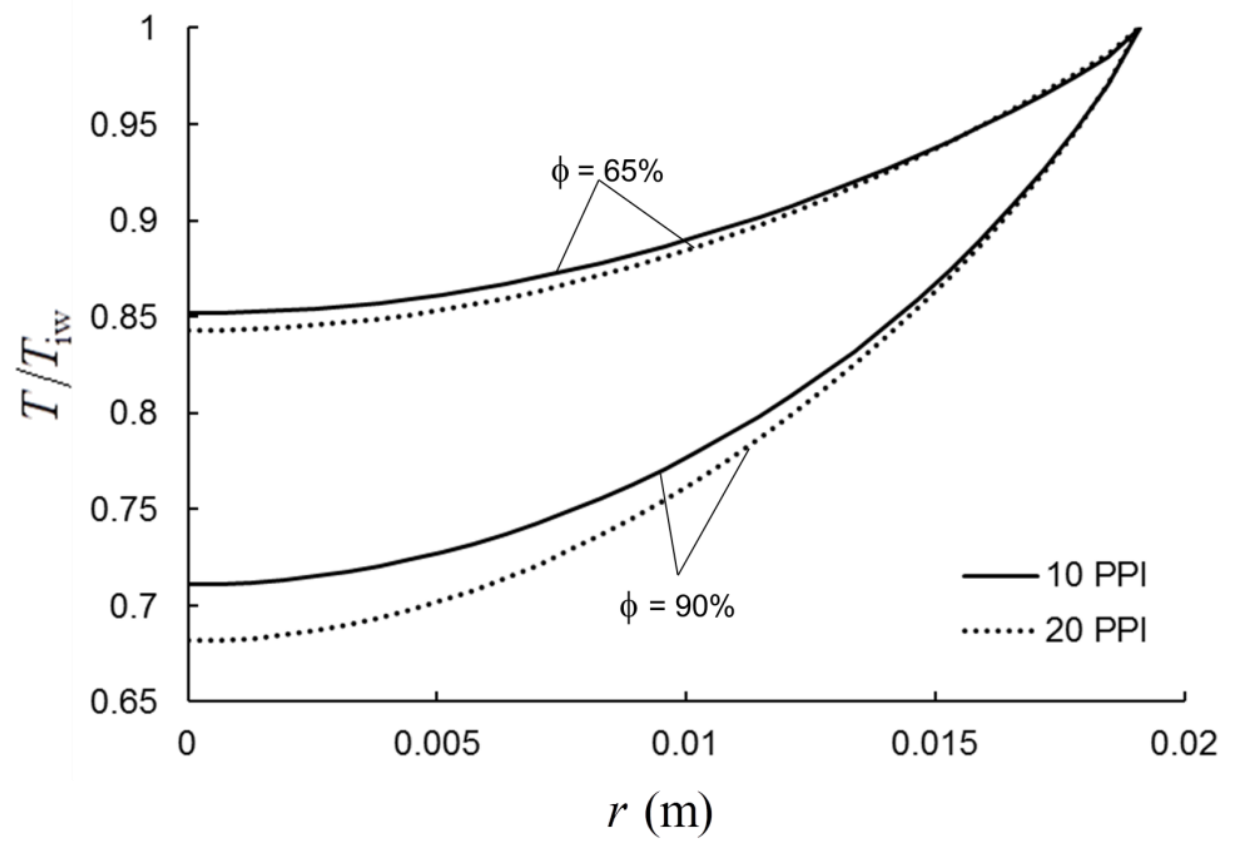

(b)

Figure 5. Normalized radial temperature profiles of the gases on the heat exchanger cold side, where, $T_{\mathrm{i}}$ is the inner tube inner wall temperature, for $L_{\mathrm{HX}}=1.4 \mathrm{~m}$, sweep gas flow rate of $1.8 \times 10^{-3} \mathrm{~kg} \mathrm{~s}^{-1}$ for 10 and 20 PPI foams with $65 \%$ and $90 \%$ porosities at (a) $\mathrm{z}=0.1 \mathrm{~m}$ and (b) $\mathrm{z}=0.7 \mathrm{~m}$. 


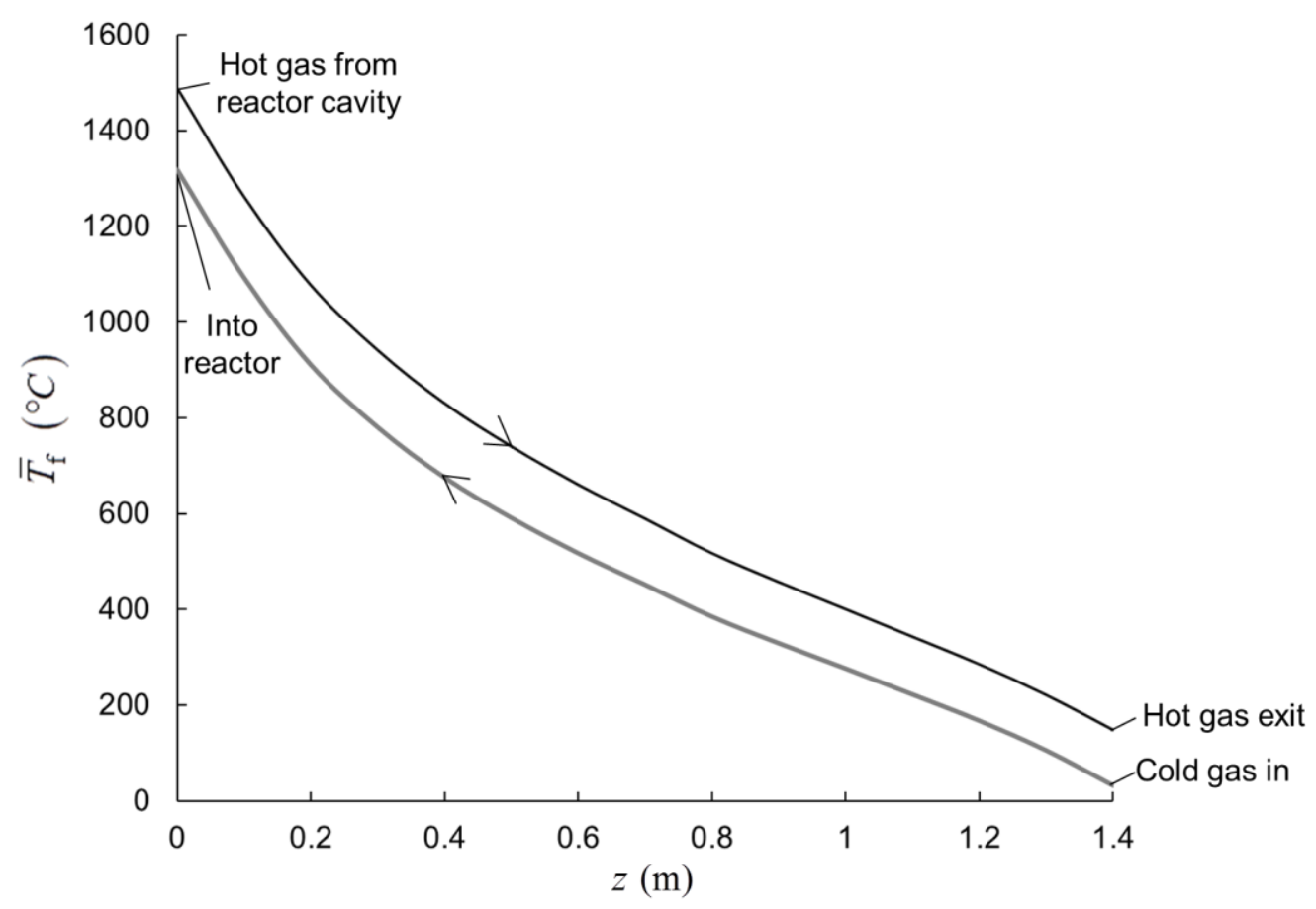

Figure 6. Bulk mean gas temperatures at various axial locations in a $1.4 \mathrm{~m}$ long heat exchanger with 10 PPI and $90 \%$ porous RPC for sweep gas flow rate of $1.8 \times 10^{-3} \mathrm{~kg} \mathrm{~s}^{-1}$.

\subsection{Optimization of solar-to-fuel efficiency}

Table 2 lists the results of the parametric study of the impact of the porosity of the 10 PPI RPC and the length of each heat exchanger on the heat exchanger effectiveness and the design (i.e., the mass of ceria) and the operation (total gas flow rates, pumping power, fuel production and efficiency) of the $3 \mathrm{~kW}_{\text {th }}$ prototype reactor. The power available for chemistry, and thus the total mass of ceria, which determines the mass flow rates and the rate of fuel production, is highly sensitive to the effectiveness of heat recovery. For example, a $1.4 \mathrm{~m}$ long heat exchanger with 10 PPI, 65\% porosity RPC provides the highest heat exchanger effectiveness ( $89 \%$ for reduction, and $92 \%$ for oxidation) and thermal duty $(3.56 \mathrm{~kW}$ for reduction, and $1.89 \mathrm{~kW}$ during oxidation) of the options considered, and yields $\mathrm{CO}$ at an average rate of $394 \mu \mathrm{mol} \mathrm{s}{ }^{-1}$ with 5100 $\mathrm{g}$ of ceria in the reactor. With $90 \%$ porosity, the heat exchanger effectiveness decreases only 
slightly to $86 \%$ for reduction and $91 \%$ for oxidation, yet fuel production is reduced by more than $18 \%$. This dramatic result demonstrates the significance of sensible heating of the reduction and oxidation gases in the overall energy budget. However, as shown by comparison of the solar-tofuel efficiency for these two examples, the benefit of improved fuel production with $65 \%$ porosity RPC is offset by an increase in pumping power. The solar-to-fuel efficiency of the integrated reactor/heat exchanger is improved from 1.9 to $2.4 \%$ with the increase in porosity from $65 \%$ to either 85 or $90 \%$. If pumping power were not included in the calculation of solar-tofuel efficiency, the predicted efficiencies would increase monotonically with decreasing porosity due to both higher fuel production and improved effectiveness of heat recuperation. Without accounting for the pumping power, the predicted efficiency is $3.7 \%$ and $3.0 \%$ for porosities of $65 \%$ and $90 \%$ respectively.

Table 2. Summary of results of parametric study of RPC porosity and heat exchanger length

\begin{tabular}{|c|c|c|c|c|c|c|c|c|c|c|c|c|c|}
\hline \multirow{2}{*}{$\begin{array}{c}\mathrm{L} \\
(\mathrm{m})\end{array}$} & \multirow{2}{*}{$\begin{array}{l}\phi \\
(\%)\end{array}$} & \multirow{2}{*}{$\begin{array}{l}m_{\text {ceria }} \\
(\mathrm{g})\end{array}$} & \multicolumn{2}{|c|}{$\Delta p_{R E}(\mathrm{kPa})$} & \multicolumn{2}{|c|}{$\Delta p_{H X}(\mathrm{kPa})$} & \multicolumn{2}{|c|}{$\begin{array}{c}\varepsilon \\
(\%)\end{array}$} & \multirow{2}{*}{$\begin{array}{c}\overline{\dot{n}}_{f} \\
\left(\mu \mathrm{mol} \mathrm{s} \mathrm{s}^{-1}\right)\end{array}$} & \multirow{2}{*}{$\begin{array}{l}Q_{\text {pump }} \\
\text { (W) }\end{array}$} & \multicolumn{2}{|c|}{$\begin{array}{c}\text { Heat duty } \\
(\mathrm{kW})\end{array}$} & \multirow{2}{*}{$\begin{array}{c}\eta \\
(\%)\end{array}$} \\
\hline & & & $\Delta p_{\mathrm{RE}, \mathrm{rd}}$ & $\Delta p_{\mathrm{RE}, \mathrm{ox}}$ & $\Delta p_{\mathrm{HX}, \mathrm{rd}}$ & $\Delta p_{\mathrm{HX}, \mathrm{ox}}$ & $\varepsilon_{\mathrm{rd}}$ & $\varepsilon_{\mathrm{ox}}$ & & & $\mathrm{Rd}$ & Ox & \\
\hline 0.35 & 65 & 2900 & 6.9 & 2.2 & 8.4 & 2.1 & 79.8 & 86.4 & 223 & 352 & 1.82 & 1.00 & 1.9 \\
\hline 0.35 & 75 & 2700 & 6.3 & 2.0 & 4.7 & 1.3 & 78.5 & 86.1 & 212 & 224 & 1.70 & 0.97 & 1.9 \\
\hline 0.35 & 80 & 2600 & 6.1 & 1.9 & 3.5 & 1.0 & 77.4 & 85.8 & 203 & 207 & 1.63 & \begin{tabular}{|l|}
0.94 \\
\end{tabular} & 1.8 \\
\hline 0.35 & 85 & 2500 & 5.6 & 1.8 & 2.4 & 0.7 & 76.5 & 85.6 & 197 & 168 & 1.53 & 0.89 & 1.8 \\
\hline 0.35 & 90 & 2400 & 5.1 & 1.7 & 1.0 & 0.5 & 74.5 & 84.9 & 184 & 123 & 1.45 & 0.85 & 1.7 \\
\hline 0.35 & 100 & 900 & 0.9 & 0.4 & 0.0 & 0.0 & 33.1 & 54.8 & 69 & 7 & 0.22 & 0.20 & 0.7 \\
\hline 0.7 & 65 & 3900 & 11.3 & 3.3 & 26.5 & 6.3 & 85.3 & 89.8 & 301 & 1094 & 2.64 & 1.44 & 2.1 \\
\hline 0.7 & 75 & 3700 & 10.4 & 3.1 & 14.7 & 3.7 & 84.3 & 89.5 & 284 & 712 & 2.47 & 1.36 & 2.2 \\
\hline 0.7 & 80 & 3600 & 9.6 & 2.9 & 10.4 & 2.7 & 83.7 & 89.5 & 277 & 564 & 2.34 & 1.30 & 2.2 \\
\hline 0.7 & 85 & 3400 & 8.8 & 2.7 & 7.1 & 1.9 & 82.9 & 89.3 & 266 & 440 & 2.30 & 1.25 & 2.2 \\
\hline 0.7 & 90 & 3200 & 8.1 & 2.5 & 4.7 & 1.3 & 81.2 & 88.7 & 245 & 329 & 2.06 & 1.17 & 2.1 \\
\hline 0.7 & 100 & 1000 & 1.0 & 0.4 & 0.0 & 0.0 & 40.6 & 54.0 & 75 & 9 & 0.31 & 0.21 & 0.7 \\
\hline 1.4 & 65 & 5100 & 17.5 & 4.7 & 72.8 & 12.5 & 89.3 & 91.8 & 394 & 2971 & 3.56 & 1.89 & 1.9 \\
\hline 1.4 & 75 & 4800 & 15.9 & 4.2 & 40.8 & 9.7 & 88.4 & 91.5 & 370 & 2018 & 3.33 & 1.79 & 2.1 \\
\hline 1.4 & 80 & 4600 & 15.2 & 4.2 & 28.0 & 7.2 & 88.1 & 91.4 & 362 & 1610 & 3.23 & 1.74 & 2.3 \\
\hline 1.4 & 85 & 4400 & 14.1 & 4.0 & 20.6 & 5.1 & 87.3 & 91.3 & 346 & 1167 & 3.10 & 1.66 & 2.4 \\
\hline 1.4 & 90 & 4100 & 12.5 & 3.6 & 13.0 & 3.0 & 86.2 & 90.9 & 322 & 819 & 2.82 & 1.54 & 2.4 \\
\hline 1.4 & 100 & 1100 & 1.2 & 0.5 & 0.0 & 0.0 & 45.5 & 60.3 & 83 & 11 & 0.38 & 0.27 & 0.8 \\
\hline
\end{tabular}


Solar-to-fuel efficiency is plotted in Figure 7(a) for heat exchanger lengths from 0.35 to $1.4 \mathrm{~m}$ and for RPC porosities from 65 to $90 \%$. For reference, the efficiency is also provided for heat exchangers without RPC (i.e. $\phi=100 \%$ ). Without RPC, efficiencies are less than half those achieved with RPC. The trends observed in Figure 7(a) are explained by the tradeoff in the power of fuel produced $\left(\overline{\dot{n}}_{f} H H V_{f}\right)$ and the pumping power that must be supplied by solar energy, $Q_{\text {pump }}$, shown Figure 7(b). For all heat exchanger lengths, the power of the fuel and the pumping power decrease with increasing porosity. When the heat exchanger length is decreased, the pumping power is reduced due to a decrease in the mass of ceria accompanied by a decrease in gas flow rates (see Table 2) as well as the reduction in length. For a $1.4 \mathrm{~m}$-long heat exchanger, pumping power decreases from $2971 \mathrm{~W}$ at $\phi=65 \%$ to $820 \mathrm{~W}$ for $\phi=90 \%$ and the reactor efficiency increases from $1.9 \%$ to $2.4 \%$. If the heat exchanger length is halved to $0.7 \mathrm{~m}$, the highest efficiency of $2.2 \%$ is achieved with lower porosity (75\% and $85 \%)$. The cost savings of decreasing the heat exchanger from $1.4 \mathrm{~m}$ to $0.7 \mathrm{~m}$ might outweigh the minimal drop in efficiency. If the heat exchanger is $0.35 \mathrm{~m}$-long, the optimal RPC porosity shifts to the lowest porosities considered (65-75\%) and the efficiency is $1.9 \%$. Even at the lowest porosity of $65 \%$, the pumping power $\left(352 \mathrm{~W}\right.$ ) is $1 / 10^{\text {th }}$ of the pumping power for $1.4 \mathrm{~m}$-long heat exchanger. As the length of the heat exchanger is reduced, the reactor efficiency is driven more by the effectiveness of heat recovery and fuel production than changes in the pumping power. Thus, the optimal porosity is shifted to lower values. 


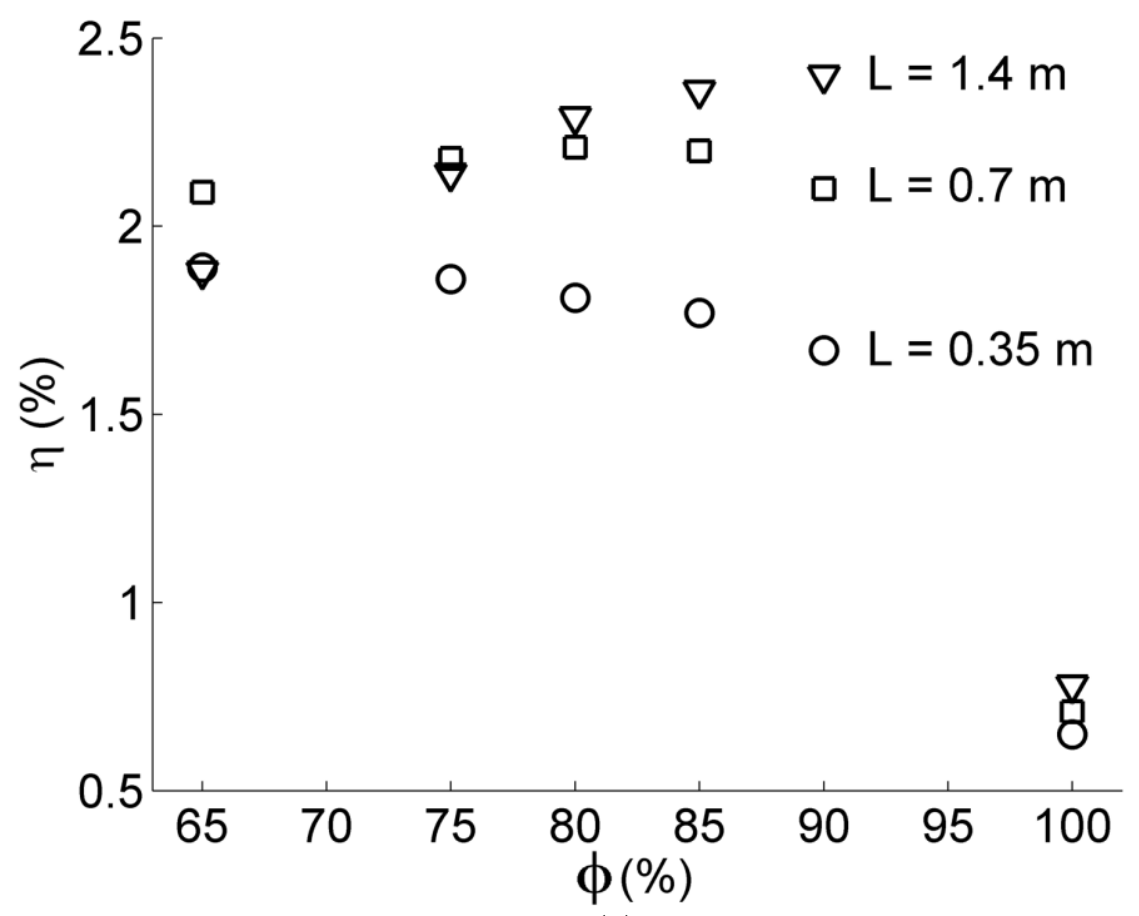

(a)

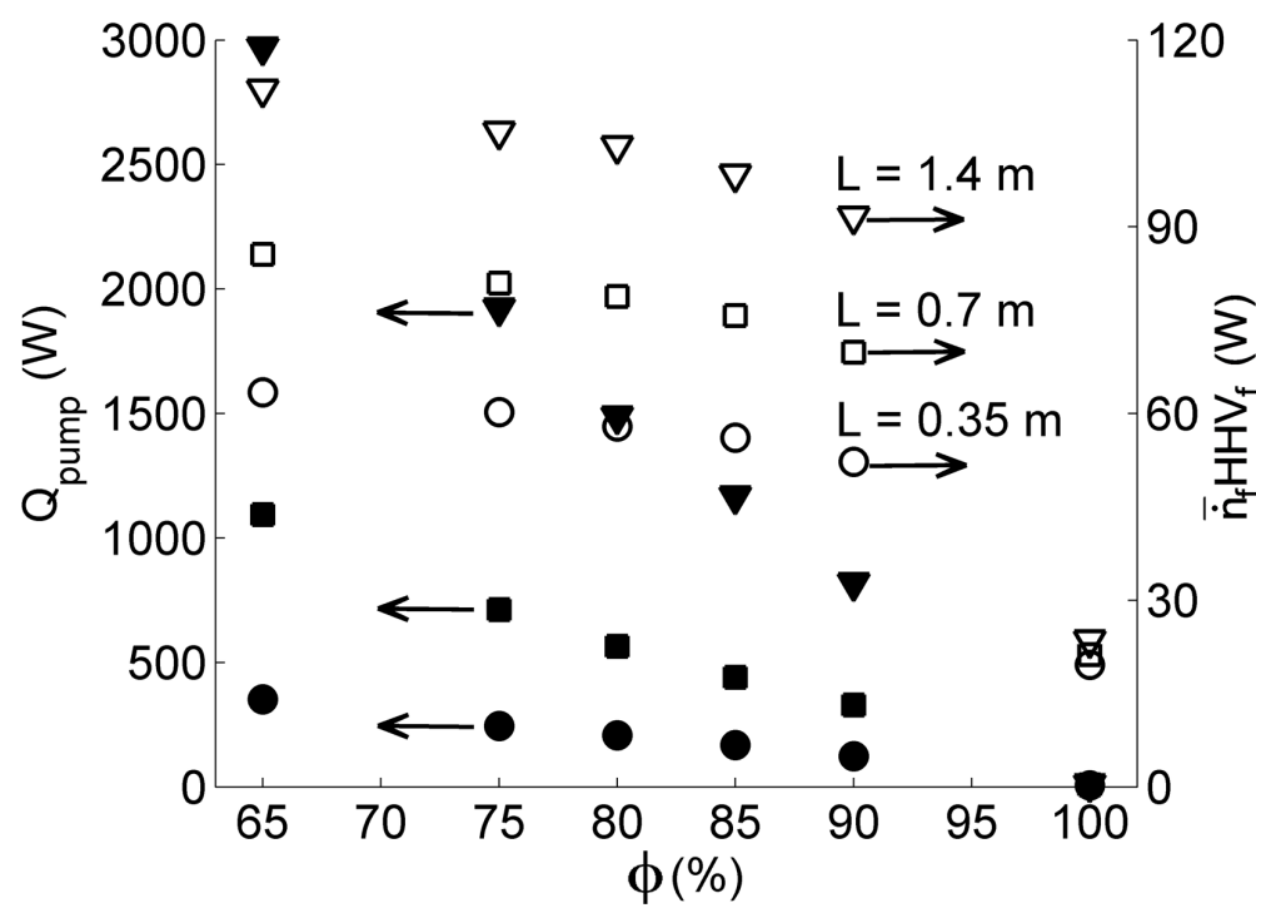

(b)

Figure 7. The impact of porosity for 10 PPI foam on (a) solar-to-fuel efficiency, and (b) pumping power requirement $\left(Q_{\text {pump }}\right)$ and power content in fuel $\left(\overline{\dot{n}}_{f} H H V_{f}\right)$. The $100 \%$ porosity data indicate the absence of RPC foam in the heat exchanger. 


\section{Conclusion}

In this paper, we analyze a counterflow heat exchanger comprising two concentric alumina tubes filled with reticulate porous alumina foam as a means of providing effective gasphase heat recovery at $1500{ }^{\circ} \mathrm{C}$ for a solar thermochemical process to split $\mathrm{CO}_{2}$ via the isothermal cerium dioxide redox cycle. A steady state, conjugate heat transfer numerical model is developed to evaluate the impact of pore size and porosity of the alumina RPC and heat exchanger length on heat transfer and pressure drop. The numerical model of the heat exchanger is coupled with an overall process energy balance of the solar reactor to select the heat exchanger design and reactor operating conditions which optimize solar-to-fuel efficiency. Foam morphologies of 10, 20, 30 PPI with porosities from 65 to $90 \%$ are considered.

The results of the CFD model highlight the significance of radiative and conductive transport in the heat exchanger. Large pores (low PPI) and high porosity minimize pressure drop and facilitate radiative transport due to improved penetration of thermal radiation in the RPC. However, at temperatures below $700{ }^{\circ} \mathrm{C}$, solid phase conduction dominates heat transfer, and for this reason the lowest porosity RPC yields the highest overall heat transfer coefficient. Thus while lower PPI foam is always preferred, selection of the porosity of the RPC requires consideration of the tradeoff between effectiveness of heat recovery and pressure drop on overall solar-to fuel efficiency of the integrated heat exchanger/reactor. Depending upon the heat exchanger length, which affects heat recovery effectiveness and pumping power, the RPC porosity required to optimize solar-to-fuel efficiency shifts. The longest heat exchanger studied $(1.4 \mathrm{~m})$ with $10 \mathrm{PPI}$, yields the highest efficiency of all the cases examined in this paper, $2.4 \%$ at $90 \%$ porosity. Halving the length of the heat exchanger to $0.7 \mathrm{~m}$ only marginally decreases the efficiency to $2.2 \%$ at a reduced porosity of $75-85 \%$. Finally, for the shortest length of $0.35 \mathrm{~m}$, 
the highest efficiency attained is $1.9 \%$ at the lowest porosity of $65 \%$. The fact that the mass of reactive material, RPC morphology and heat exchanger length are mutually dependent parameters to optimize process efficiency reinforces the sensitivity of solar-to-fuel efficiency to effectiveness of heat recovery and pressure drop (includes the reactive element) in recuperator.

In conclusion, the proposed counter-flow, tubular heat exchanger filled with alumina RPC shows the potential to provide adequate heat transfer and acceptable pressure drop for this application.

\section{Acknowledgments}

The financial support by the U.S. Department of Energy's ARPAe (award no. DE AR0000182) to the University of Minnesota is gratefully acknowledged. The authors acknowledge the helpful discussions with Prof. Tom Chase and Stephen Sedler on integration of the heat exchanger with the reactor. The computing facilities provided by the Minnesota Supercomputing Institute (MSI) at the University of Minnesota were used to conduct this research. 


\section{References}

[1] R.J. Panlener, R.N. Blumenthal, J.E. Garnier, A Thermodynamic Study of Nonstoichiometric Cerium Dioxide, J. Phys. Chem. Solids. 36 (1975) 1213-1222. doi:10.1016/0022-3697(75)90192-4.

[2] W.C. Chueh, S.M. Haile, A Thermochemical Study of Ceria: Exploiting an Old Material for New Modes of Energy Conversion and CO2 Mitigation., Philos. Trans. A. Math. Phys. Eng. Sci. 368 (2010) 3269-94. doi:10.1098/rsta.2010.0114.

[3] J. Lapp, J.H. Davidson, W. Lipiński, Efficiency of Two-step Solar Thermochemical Nonstoichiometric Redox Cycles with Heat Recovery, Energy. 37 (2012) 591-600. doi:10.1016/j.energy.2011.10.045.

[4] J. Lapp, J.H. Davidson, W. Lipiński, Heat Transfer Analysis of a Solid-Solid Heat Recuperation System for Solar-Driven Nonstoichiometric Redox Cycles, J. Sol. Energy Eng. 135 (2013) 031004. doi:10.1115/1.4023357.

[5] I. Ermanoski, N.P. Siegel, E.B. Stechel, A New Reactor Concept for Efficient SolarThermochemical Fuel Production, J. Sol. Energy Eng. 135 (2013) 031002. doi:10.1115/1.4023356.

[6] R. Bader, L.J. Venstrom, J.H. Davidson, W. Lipiński, Thermodynamic Analysis of Isothermal Redox Cycling of Ceria for Solar Fuel Production, Energy \& Fuels. 27 (2013) 5533-5544. doi:10.1021/ef400132d.

[7] Y. Hao, C.K. Yang, S.M. Haile, High-temperature isothermal chemical cycling for solardriven fuel production., Phys. Chem. Chem. Phys. 15 (2013) 17084-92. doi:10.1039/c3cp53270d.

[8] L.J. Venstrom, R.M. De Smith, Y. Hao, S.M. Haile, J.H. Davidson, Efficient Splitting of $\mathrm{CO}_{2}$ in an Isothermal Redox Cycle Based on Ceria, Energy \& Fuels. 28 (2014) 27322742. doi:10.1021/ef402492e.

[9] I. Ermanoski, J.E. Miller, M.D. Allendorf, Efficiency Maximization in SolarThermochemical Fuel Production: Challenging the Concept of Isothermal Water Splitting., Phys. Chem. Chem. Phys. (2014) 8418-8427. doi:10.1039/c4cp00978a.

[10] W.C. Chueh, C. Falter, M. Abbott, D. Scipio, P. Furler, S.M. Haile, et al., High-flux Solar-driven Thermochemical Dissociation of $\mathrm{CO}_{2}$ and $\mathrm{H}_{2} \mathrm{O}$ Using Nonstoichiometric Ceria., Science. 330 (2010) 1797-801. doi:10.1126/science.1197834. 
[11] P. Furler, J. Scheffe, M. Gorbar, L. Moes, U. Vogt, A. Steinfeld, Solar Thermochemical $\mathrm{CO}_{2}$ Splitting Utilizing a Reticulated Porous Ceria Redox System, Energy \& Fuels. 26 (2012) 7051-7059. doi:10.1021/ef3013757.

[12] P. Furler, J. Scheffe, D. Marxer, M. Gorbar, A. Bonk, U. Vogt, A. Steinfeld, Thermochemical $\mathrm{CO}_{2}$ Splitting via Redox Cycling of Ceria Reticulated Foam Structures with Dual-Scale Porosities., Phys. Chem. Chem. Phys. 16 (2014) 10503-10511. doi:10.1039/c4cp01172d.

[13] P. Furler, J.R. Scheffe, A. Steinfeld, Syngas Production by Simultaneous Splitting of $\mathrm{H}_{2} \mathrm{O}$ and $\mathrm{CO}_{2}$ via Ceria Redox Reactions in a High-temperature Solar Reactor, Energy Environ. Sci. 5 (2012) 6098-6103. doi:10.1039/c1ee02620h.

[14] C.F. McDonald, The Role of the Ceramic Heat Exchanger in Energy and Resource Conservation, J. Eng. Power. 102 (1980) 303-315. doi:10.1115/1.3230253.

[15] C.A. Lewinsohn, M.A. Wilson, J.R. Fellows, H.S. Anderson, Fabrication and Joining of Ceramic Compact Heat Exchangers for Process Integration, Int. J. Appl. Ceram. Technol. 9 (2012) 700-711. doi:10.1111/j.1744-7402.2012.02788.x.

[16] R. Smyth, The use of high temperature heat exchangers to increase power plant thermal efficiency, in: IECEC-97 Proc. Thirty-Second Intersoc. Energy Convers. Eng. Conf. (Cat. No.97CH6203), IEEE, 1997: pp. 1690-1695. doi:10.1109/IECEC.1997.656676.

[17] A. Sommers, Q. Wang, X. Han, C. T'Joen, Y. Park, A. Jacobi, Ceramics and ceramic matrix composites for heat exchangers in advanced thermal systems-A review, Appl. Therm. Eng. 30 (2010) 1277-1291. doi:10.1016/j.applthermaleng.2010.02.018.

[18] Q. Li, G. Flamant, X. Yuan, P. Neveu, L. Luo, Compact heat exchangers: A review and future applications for a new generation of high temperature solar receivers, Renew. Sustain. Energy Rev. 15 (2011) 4855-4875. doi:10.1016/j.rser.2011.07.066.

[19] V. Ponyavin, Y. Chen, T. Mohamed, M. Trabia, A.E. Hechanova, M. Wilson, Design of a Compact Ceramic High-Temperature Heat Exchanger and Chemical Decomposer for Hydrogen Production, Heat Transf. Eng. 33 (2012) 853-870. doi:10.1080/01457632.2012.654446.

[20] F. Meschke, A. Kayser, Plate heat exchanger: Method for its production and its use, US Patent No. 20090151917, 2009.

[21] J. Schmidt, M. Scheiffele, M. Crippa, P.F. Peterson, E. Urquiza, K. Sridharan, et al., Design, Fabrication, and Testing of Ceramic Plate-Type Heat Exchangers with Integrated Flow Channel Design, Int. J. Appl. Ceram. Technol. 8 (2011) 1073-1086. doi:10.1111/j.1744-7402.2010.02573.x. 
[22] R.G. Munro, Material Properties of a Sintered $\alpha$-SiC, J. Phys. Chem. Ref. Data. 26 (1997) 1195 - 1201. doi:10.1063/1.556000.

[23] P.J. Jorgensen, M.E. Wadsworth, I.B. Cutler, Effects of Water Vapor on Oxidation of Silicon Carbide, J. Am. Ceram. Soc. 44 (1961) 258-261. doi:10.1111/j.11512916.1961.tb15374.x.

[24] J.M. Warren, High temperature oxidation of Silicon carbide, M.S. Thesis, Air Force Institute of Technology, 1972.

[25] J. Wang, L. Zhang, Q. Zeng, G.L. Vignoles, A. Guette, Theoretical Investigation for the Active-to-Passive Transition in the Oxidation of Silicon Carbide, J. Am. Ceram. Soc. 91 (2008) 1665-1673. doi:10.1111/j.1551-2916.2008.02353.x.

[26] A.H. McDaniel, Solar hydrogen production with a metal oxide-based thermochemical cycle, FY 2012 Annual Progress Report, Sandia National Laboratories, 2012.

[27] W. Lu, C.Y. Zhao, S.A. Tassou, Thermal analysis on metal-foam filled heat exchangers. Part I: Metal-foam filled pipes, Int. J. Heat Mass Transf. 49 (2006) 2751-2761. doi:10.1016/j.ijheatmasstransfer.2005.12.012.

[28] C.Y. Zhao, W. Lu, S.A. Tassou, Thermal analysis on metal-foam filled heat exchangers. Part II: Tube heat exchangers, Int. J. Heat Mass Transf. 49 (2006) 2762-2770. doi:10.1016/j.ijheatmasstransfer.2005.12.014.

[29] C. Yang, A. Nakayama, W. Liu, Heat transfer performance assessment for forced convection in a tube partially filled with a porous medium, Int. J. Therm. Sci. 54 (2012) 98-108. doi:10.1016/j.ijthermalsci.2011.10.023.

[30] Z.G. Qu, H.J. Xu, W.Q. Tao, Fully developed forced convective heat transfer in an annulus partially filled with metallic foams: An analytical solution, Int. J. Heat Mass Transf. 55 (2012) 7508-7519. doi:10.1016/j.ijheatmasstransfer.2012.07.048.

[31] M.F. Modest, Approximate solution methods for one-dimensional media, in: Radiat. Heat Transf., Second, Academic Press, 2003: pp. 451-456.

[32] C.Y. Zhao, T.J. Lu, H.P. Hodson, J.D. Jackson, The temperature dependence of effective thermal conductivity of open-celled steel alloy foams, Mater. Sci. Eng. A. 367 (2004) 123-131. doi:10.1016/j.msea.2003.10.241.

[33] C.Y. Zhao, T.J. Lu, H.P. Hodson, Thermal radiation in ultralight metal foams with open cells, Int. J. Heat Mass Transf. 47 (2004) 2927-2939. doi:10.1016/j.ijheatmasstransfer.2004.03.006. 
[34] Z. Wu, C. Caliot, G. Flamant, Z. Wang, Coupled radiation and flow modeling in ceramic foam volumetric solar air receivers, Sol. Energy. 85 (2011) 2374-2385.

doi:10.1016/j.solener.2011.06.030.

[35] I. Hischier, Experimental and Numerical Analyses of a Pressurized Air Receiver for SolarDriven Gas Turbines, J. Sol. Energy Eng. 134 (2012) 021003. doi:10.1115/1.4005446.

[36] M. Kaviany, Principles of heat transfer in Porous media, Second, Springer-Verlag, New York, 1995.

[37] S. Patankar, Source-Term Linearization, in: M.A. Phillips, E.M. Millman (Eds.), Numer. Heat Transf. Fluid Flow, Hemisphere Publishing Corporation, 1980: pp. 143-145.

[38] ANSYS® Academic Research, Ansys Fluent User Defined Functions Guide, Release 15.0, (2011) 1715-1762. http://www/ansys.com.

[39] J.R. Markham, P.R. Solomon, P.E. Best, An FT-IR based instrument for measuring spectral emittance of material at high temperature, Rev. Sci. Instrum. 61 (1990) 3700. doi:10.1063/1.1141538.

[40] P. Hsu, J.R. Howell, Measurements of thermal conductivity and optical properties of porous partially stabilized zirconia, Exp. Heat Transf. 5 (1992) 293-313.

doi:10.1080/08916159208946446.

[41] T.J. Hendricks, J.R. Howell, Absorption/Scattering Coefficients and Scattering Phase Functions in Reticulated Porous Ceramics, J. Heat Transfer. 118 (1996) 79-87. doi:10.1115/1.2824071.

[42] M.J. Hale, M.S. Bohn, Measurement of the radiative transport properties of reticulated alumina foams, in: Conf. Sol. '93 Am. Soc. Mech. Eng. (ASME)/American Sol. Energy Soc. Jt. Sol. Energy Conf., Washington, DC, 1992. http://www.osti.gov/scitech/biblio/10113519 (accessed January 30, 2014).

[43] M.F. Modest, The Method of Spectral Harmonics (PN-Approximation), in: Radiat. Heat Transf., Second, Academic Press, 2003: pp. 465-492.

[44] A. Bhattacharya, V.V. Calmidi, R. Mahajan, Thermophysical properties of high porosity metal foams, Int. J. Heat Mass Transf. 45 (2002) 1017-1031. doi:10.1016/S00179310(01)00220-4.

[45] V. V. Calmidi, Transport phenomena in high porosity fibrous metal foams, University of Colorado Boulder, 1998.

[46] S. Ergun, Fluid flow through packed bed columns, Chem. Eng. Prog. 48 (1952) 89 -94. 
[47] M. Lacroix, P. Nguyen, D. Schweich, C. Pham Huu, S. Savin-Poncet, D. Edouard, Pressure drop measurements and modeling on SiC foams, Chem. Eng. Sci. 62 (2007) 3259-3267. doi:10.1016/j.ces.2007.03.027.

[48] Z. Wu, C. Caliot, F. Bai, G. Flamant, Z. Wang, J. Zhang, et al., Experimental and numerical studies of the pressure drop in ceramic foams for volumetric solar receiver applications, Appl. Energy. 87 (2010) 504-513. doi:10.1016/j.apenergy.2009.08.009.

[49] J. Petrasch, F. Meier, H. Friess, A. Steinfeld, Tomography based determination of permeability, Dupuit-Forchheimer coefficient, and interfacial heat transfer coefficient in reticulate porous ceramics, Int. J. Heat Fluid Flow. 29 (2008) 315-326. doi:10.1016/j.ijheatfluidflow.2007.09.001.

[50] A.A. Zukauskas, Convective heat transfer in cross-flow, in: S. Kakaç, R.K. Shah, W. Aung (Eds.), Handb. Single-Phase Convect. Heat Transf., Wiley, New York, 1987.

[51] Z. Wu, C. Caliot, G. Flamant, Z. Wang, Numerical simulation of convective heat transfer between air flow and ceramic foams to optimise volumetric solar air receiver performances, Int. J. Heat Mass Transf. 54 (2011) 1527-1537. doi:10.1016/j.ijheatmasstransfer.2010.11.037.

[52] V.V. Bhattacharya, A., Calmidi, R.L. Mahajan, An Analytical-Experimental Study for the Determination of the Effective Thermal Conductivity of High Porosity Fibrous Foams, in: R.M. Sullivan (Ed.), Appl. Porous Media Methods Eng. Mater., 1999: pp. 13-20.

[53] J.G. Fourie, J.P. Du Plessis, Effective and coupled thermal conductivities of isotropic open-cellular foams, AIChE J. 50 (2004) 547-556. doi:10.1002/aic.10049.

[54] M.A. Schuetz, L.R. Glicksman, A Basic Study of Heat Transfer Through Foam Insulation, J. Cell. Plast. 20 (1984) 114-121. doi:10.1177/0021955X8402000203.

[55] R. Coquard, M. Loretz, D. Baillis, Conductive Heat Transfer in Metallic/Ceramic OpenCell Foams, Adv. Eng. Mater. 10 (2008) 323-337. doi:10.1002/adem.200700331.

[56] K. Kamiuto, Modeling of Composite Heat Transfer in Open-Cellular Porous Materials and High Temperatures, in: A. Öchsner, G.E. Murch, M.J.S. de Lemos (Eds.), Cell. Porous Mater. Therm. Prop. Simul. Predict., Wiley-VCH Verlag GmbH \& Co. KGaA, 2008: pp. 165-198.

[57] C. Yaws, Transport Properties of Chemicals and Hydrocarbons:, Electronic, Knovel, New York, 2010.

[58] M. Binnewies, E. Milke, Thermochemical Data of Elements and Compounds, Wiley-VCH Verlag GmbH \& Co. KGaA, 2002. 
[59] ANSYS® Academic Research, Ansys Fluent Users Guide, Release 15.0, (2011) 17151762. http://www.ansys.com.

[60] A. Meier, E. Bonaldi, G.M. Cella, W. Lipinski, D. Wuillemin, Solar chemical reactor technology for industrial production of lime, Sol. Energy. 80 (2006) 1355-1362. doi:10.1016/j.solener.2005.05.017.

[61] H.W. Häring, The Air Gases Nitrogen, Oxygen and Argon, in: H.-W. Häring (Ed.), Ind. Gases Process., Wiley-VCH Verlag GmbH \& Co. KGaA, Germany, 2008: pp. 9-109.

[62] M.J. Moran, H.N. Shapiro, D.D. Boettner, M.B. Bailey, Fundamentals of Engineering Thermodynmics, 7th ed., Wiley, 2010.

[63] T. Mancini, P. Heller, B. Butler, B. Osborn, W. Schiel, V. Goldberg, et al., Dish-Stirling Systems: An Overview of Development and Status, J. Sol. Energy Eng. 125 (2003) 135. doi:10.1115/1.1562634. 